Portland State University

PDXScholar

$11-2009$

\title{
Co-Evolution of Transportation and Land Use: Modeling HIstorical Dependencies in Land Use and Decision-Making
}

\author{
Lei Zhang \\ University of Maryland at College Park \\ Wei Zu \\ University of Maryland at College Park \\ Mingxin Li \\ University of Maryland at College Park
}

Follow this and additional works at: https://pdxscholar.library.pdx.edu/trec_reports

Part of the Transportation Commons, Urban Studies Commons, and the Urban Studies and Planning Commons

Let us know how access to this document benefits you.

\section{Recommended Citation}

Zhang, Lei, Wei Xu, and Mingxin Li. Co-Evolution of Transportation and Land Use: Modeling HIstorical Dependencies in Land Use and Decision-Making. OTREC-09-07. Portland, OR: Transportation Research and Education Center (TREC), 2009. https://doi.org/10.15760/trec.96

This Report is brought to you for free and open access. It has been accepted for inclusion in TREC Final Reports by an authorized administrator of PDXScholar. Please contact us if we can make this document more accessible: pdxscholar@pdx.edu. 


\section{S)OTREC}

FINAL REPORT

\section{Co-Evolution of Transportation and Land Use: Modeling Historical Dependencies in Land Use and Transportation Decision Making}

OTREC-RR-09-08

November 2009 



\title{
CO-EVOLUTION OF TRANSPORTATION AND LAND USE: MODELING HISTORICAL DEPENDENCIES IN LAND USE AND TRANSPORTAION DECISION-MAKING
}

\section{Final Report}

\section{OTREC-RR-09-08}

\author{
By \\ Lei Zhang \\ Assistant Professor \\ $\&$ \\ Wei Xu and Mingxin Li \\ Graduate Research Assistants
University of Maryland - College Park
1173 Glenn L. Martin Hall, Bldg 088
College Park, MD 20742
for \\ Oregon Transportation Research \\ and Education Consortium (OTREC) \\ P.O. Box 751 \\ Portland, OR 97207-0751

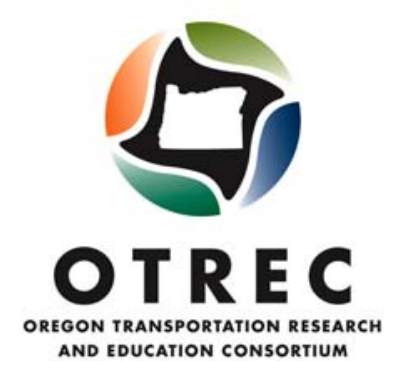

November 2009 



\begin{tabular}{|c|c|c|}
\hline $\begin{array}{l}\text { 1. Report No. } \\
\text { OTREC-RR-09-07 }\end{array}$ & 2. Government Accession No. & 3. Recipient's Catalog No. \\
\hline \multirow{2}{*}{\multicolumn{2}{|c|}{$\begin{array}{l}\text { 4. Title and Subtitle } \\
\text { CO-EVOLUTION OF TRANSPORTATION AND LAND USE: MODELING HISTORICAL } \\
\text { DEPENDENCIES IN LAND USE AND DECISION-MAKING }\end{array}$}} & $\begin{array}{l}\text { 5. Report Date } \\
\text { JNovember } 2009\end{array}$ \\
\hline & & 6. Performing Organization Code \\
\hline \multicolumn{2}{|l|}{$\begin{array}{l}\text { 7. Author(s) } \\
\text { Lei Zhang } \\
\text { Wei Xu } \\
\text { Mingxin Li }\end{array}$} & 8. Performing Organization Report No. \\
\hline \multirow{2}{*}{\multicolumn{2}{|c|}{$\begin{array}{l}\text { 9. Performing Organization Name and Address } \\
\\
\text { Department of Civil \& Environmental Engineering } \\
\text { 1173 Blenn L. Martin Hall } \\
\text { Bldg \#088 } \\
\text { University of Maryland } \\
\text { College Park, MD } 20742\end{array}$}} & 10. Work Unit No. (TRAIS) \\
\hline & & 11. Contract or Grant No. \\
\hline \multirow{2}{*}{\multicolumn{2}{|c|}{ 12. Sponsoring Agency Name and Address }} & 13. Type of Report and Period Covered \\
\hline & & 14. Sponsoring Agency Code \\
\hline
\end{tabular}

15. Supplementary Notes

16. The interaction between land use and transportation has long been the central issue in urban and regional planning. Models of such interactions provide vital information to support many public policy decisions, such as land supply, infrastructure provision, and growth management. Both the transportation and land use systems exhibit historical dependencies in policy decisions. For instance, the expansion of a roadway today will change travel demand patterns, and make certain other roads more or less likely to be expanded in the future. A specific land supply decision made at one point in time, by changing the relative attractiveness of other areas in the region, can have a profound impact on future land supply decisions. Today's land use decisions clearly influence future transportation policies and vice versa.

This project examines the land use-transportation interaction from an evolutionary perspective - once a certain set of goals are determined and pursued by politicians and planners, their land supply and transportation investment decisions are, to a large extent, driven by their previous decisions and supply-demand dynamics in the urban system. Built upon this recognition of historical dependency and a transportation network growth model previously developed by the P.I., a model of the co-evolution of land use and transportation is proposed in this project. Different from existing integrated land use and transportation models that assume exogenous network investment decisions, the co-evolution model considers both land use growth and transportation network growth as endogenous and market-driven. The central research question is how market and policies translate into transportation facilities and land use developments on the ground. The co-evolution model achieves an Urban Growth Equilibrium, which is a useful concept for planning and policy analysis. An agent-based simulation approach is employed to integrate an existing land use model and the transportation network growth model.

17. Key Words

Land supply, land use, infrastructure provision, growth management, transportation policy, Urban Growth Equilibrium,

19. Security Classification (of this report)
20. Security Classification (of this page)
18. Distribution Statement

\begin{tabular}{|l|l|}
\hline $\begin{array}{l}\text { 21. No. of Pages } \\
65\end{array}$ & 22. Price \\
\hline
\end{tabular}




\section{ACKNOWLEDGEMENTS}

This project was funded by the Oregon Transportation Research and Education Consortium (OTREC).

\section{DISCLAIMER}

The contents of this report reflect the views of the authors, who are solely responsible for the facts and the accuracy of the material and information presented herein. This document is disseminated under the sponsorship of the U.S. Department of Transportation University Transportation Centers Program and OTREC in the interest of information exchange. The U.S. Government and OTREC assume no liability for the contents or use thereof. The contents do not necessarily reflect the official views of the U.S. Government or OTREC. This report does not constitute a standard, specification, or regulation. 


\section{TABLE OF CONTENTS}

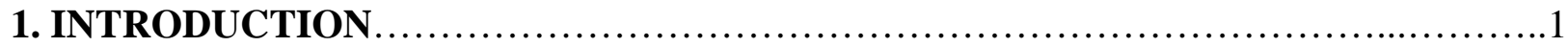

1.1. The Evolution of Transportation and Land Use Systems.........................1

1.2. Research Objectives and Scope.............................................. 3

1.3. Organization of the Project Report...........................................4

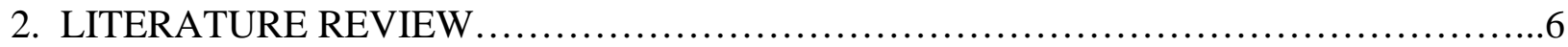

2.1. Transportation Network Growth............................................

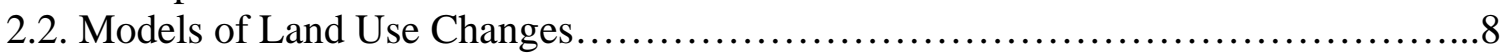

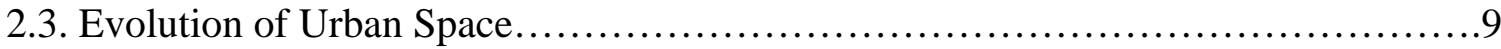

3. THEORT: LAND USE AND TRANSPORTATION NETWORK DYNAMICS AT THE MICROSCOPIC LEVEL ..............................................................11

3.1. The Dynamics of Transportation Network Growth..............................11

3.2. Integrated Land Use and Transportation Dynamics............................15

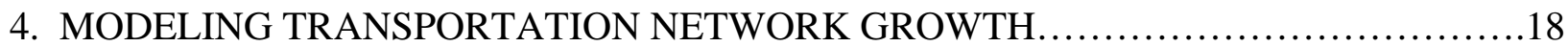

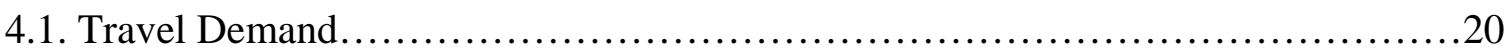

4.2. Revenue and Cost...........................................................22

4.3. Investment Rules..........................................................24

4.4. Discussion on Model Calibration and Validation...............................26

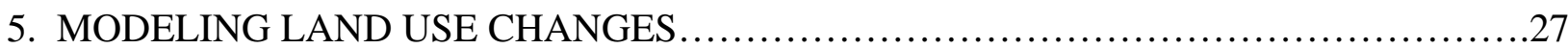

5.1. Accessibility Measures...................................................27

5.2. A Modified Land Use Change Indicator Model................................28

6. A MODEL OF LAND USE - TRANSPORTATION CO-EVOLUTION....................31

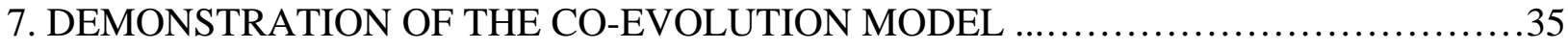

7.1. The Land Use and Transportation System Growth in a Hypothetical City...........35

7.2. A Large-Scale Application in the Twin Cities Metropolitan Area....................39

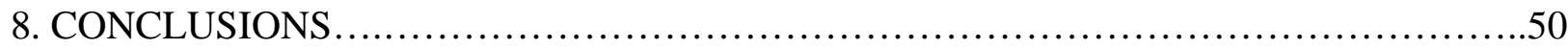

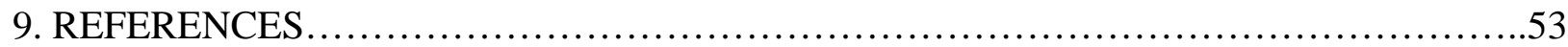




\section{LIST OF FIGURES}

Figure 3.1. Land Use-Transportation Integration....................................... 15

Figure 3.2. Feedbacks in a Co-Evolving Land Use-Transportation System....................17

Figure 4.1. Flowchart of the Transportation Network Growth Model.........................19

Figure 4.2. Link Capacity and Free-Flow Speed Relationship..............................25

Figure 6.1. A Co-Evolution Model of Land Use and Transportation..........................32

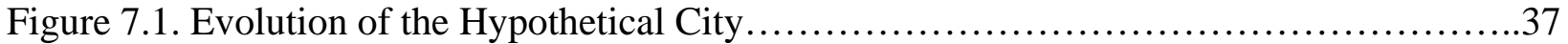

Figure 7.2. Land Use Changes Over Time in Experiment 2.................................39

Figure 7.3. Convergence Properties of the Co-Evolution Model............................42

Figure 7.4. Experiment 2 vs. Observed Network Growth after 20 Years......................43

Figure 7.5. Road Hierarchy after 20 Years..............................................44

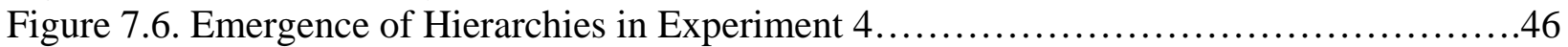

Figure 7.7. Network Congestion after 20 Years.......................................48 


\section{LIST OF TABLES}

Table 6.1. Coefficients in the Co-Evolution Model of Land Use and Transportation..............33

Table 7.1. Four simulation experiments for Twin Cities, MN.............................40 


\section{INTRODUCTION}

\subsection{The Evolution of Transportation and Land Use Systems}

Transportation networks grow and decline in response to changing travel demand and technology. In 1900 there were 240 kilometers of paved road in the United States (1), and this total had increased to 6.4 million by 2000 (2). Transportation agencies at the federal, state, and local levels are still making routine capacity expansion decisions to achieve mobility and accessibility objectives. Similarly, population and economic growth tends to impose increasing demand on developable land. Since the 1970s, the urban growth boundary in Portland, OR., has been expanded three dozen times - with five major expansions in the last eight years - to accommodate increased population and economic activities. The growth of transportation networks and the growth of land use both affect the social and economic activities that a region can support, yet the dynamics of how they occur and interact with each other is one of the least understood areas in transportation, geography, and regional science. In reality, their interactions have profound impact on the quality of life of millions and of society as a whole. The current low-density, sprawled, land use patterns in many U.S. cities are largely due to the growth of the U.S. roadway network, while this specific land use pattern in turn limits the growth of certain transportation networks (e.g., public transit).

This lack of understanding is revealed time and again in the long-range planning efforts of metropolitan planning organizations (MPOs), where transportation network change is treated exclusively as the result of top-down decision-making. Non-immediate and non-local effects are generally underestimated in planning practices because the complete network effects are incomprehensible with the current tools, which often results in myopic network expansion decisions. If one looks at the complexity and bureaucracy involved in transportation 
infrastructure investment, one might conclude that it is almost impossible to model the land use and transportation network growth endogenously. However, changes to the land use and transportation systems are rather the results of numerous small decisions (and some large ones) by property owners, firms, developers, towns, cities, counties, state transportation departments, MPOs, and states in response to market conditions and policy initiatives. Though institutions make network growth (decline) happen on the surface, network dynamics are indeed driven by some underlying natural market forces and, hence, are predictable.

In a series of previous research papers (Zhang and Levinson 2003, Zhang and Levinson 2006, Zhang et al. 2008, Zhang 2009), the P.I. and his colleagues have developed a prototype Simulator Of Network Growth (SONG) that integrates component models of travel demand, infrastructure provision and maintenance, and network pricing/investment policies to forecast future transportation network growth under different policy scenarios and their welfare consequences. The transportation network growth model has found applications in areas such as road pricing, strategic infrastructure investment, and network ownership policies. One limitation of the SONG model is that land use growth is considered exogenous to the transportation system.

On the other hand, models of land use growth have been developed to address various urban design and planning issues. Oregon has been a strong proponent of integrated land use and transportation planning. Well-known models of land use dynamics such as UrbanSim (10) and TRANUS (11) have been tested in Oregon cities and in the statewide planning process. Portland Metro (the regional MPO) and the Oregon Department of Transportation (ODOT) also have developed their own land use models including Metroscope (12) and LUSDR (13), which have been successfully applied in Portland and smaller urban areas in Oregon. However, these 
existing models of land use growth all assume exogenous transportation infrastructure investments.

A co-evolution model of transportation network growth and land use growth can remove the limitations of both the SONG network growth model and the aforementioned models of land use dynamics. Such a co-evolution model would significantly improve the evaluation of urban policies that cause significant land use and/or transportation network changes. Previous surveys and planning studies in Oregon have assembled a wealth of high-quality land use and transportation network data. For instance, the Eugene-Springfield region has archived a dataset with longitudinal information of land use and transportation network changes, which would support the development of the co-evolution model of land use and transportation.

\subsection{Research Objectives and Scope}

Understanding how markets and policies translate into transportation facilities and land use developments on the ground is essential for both scientific understanding and improving forecasting, planning, policy-making, and evaluation. This research endeavors to understand the evolutionary growth process of transportation networks and land use at the theoretical level, and develop a prototype model of the co-evolution of transportation and land use. The growth of transportation networks and the growth of land use, as well as their interactions, will be considered jointly in the co-evolution model.

The proposed model can fill a gap in the field of integrated land use and transportation planning, where existing models only partially consider the interdependence between infrastructure growth and land use growth. More specifically, the existing models recognize that transportation network (land use) growth causes land use (transportation network) changes, but 
ignore the feedback effect that the new land use (network) changes in turn lead to further network (land use) changes. The co-evolution model allows this iterative process to continue until an Urban Growth Equilibrium is achieved, therefore more accurately capturing the longterm system impact of land use and transportation policies. Key research questions to be examined include:

(1). Why do transportation networks grow and decline, and why do land use patterns shift?

(2). How do transportation network growth and land use growth interact with each other?

(3). How can transportation and land use planning be improved to take advantage of a new understanding of the transportation and land use co-evolution?

Since this project is a "small start" project funded by the Oregon Transportation Research and Education Consortium (OTREC), the mandatory one-year schedule for all "small start" projects requires a limited project scope. As the first step toward an integrated model of transportation network and land use growth, this project focuses on the demonstration of the evolutionary modeling concept through the development of a prototype co-evolution model and the identification of its application areas. Comprehensive model validation and real-world applications are left for future research.

\subsection{Organization of the Project Report}

The remainder of this project repot is organized as follows. Section 2 provides a review of related literature in regional science, urban economics, regional planning, and transportation. Though the reviewed studies have dissimilar objectives and methodologies, they all shed some light on the nature of land use and transportation network growth and the associated socio- 
economic impact. Section 3 presents a theoretical framework for studying the co-evolution of land use and transportation. The framework helps identify various influencing factors and interdependences among those factors in a land use-transportation system. Section 4 describes an improved version of the simulator of transportation network growth. Section 5 develops a land use change indicator model that estimates land use changes over time. The transportation growth model and the land use model are integrated in Section 6. The resulting co-evolution model of land use and transportation is demonstrated in two case studies in Section 7. Once case study examines a small contrived grid network system, and the other case study applies the coevolution model to the Twin Cities, MN, metropolitan area. Conclusions and future research directions are offered in Section 8. 


\section{LITERATURE REVIEW}

A transportation network is a complex system that exhibits the properties of self-organization and emergence. Previous research in dynamics related to transportation networks focuses on traffic assignment or traffic management. However, the dynamics of transportation network growth have not been adequately studied. If a transportation network is represented by a directed graph, there are several important questions yet to be answered: (1) How do the existing links (roads) develop and degenerate?; (2) How are new links added to the existing network?; (3) How are new nodes added to the existing network?; (4) Do networks self-organize into hierarchical patterns?; and (5) Are roads (routes) an emergent property of networks?

One of the few previous studies (Yerra and Levinson 2002) in this area shows that, even starting from a random or a uniform pattern, a transportation network tends to self-organize into a hierarchical pattern in which some roads attract more traffic, receive proper maintenance, and are gradually expanded while other roads are less popular, poorly maintained, and may eventually be abandoned. It is also demonstrated that although this hierarchical pattern seems to be designed by planners and engineers, it is actually an intrinsic emergent property of networks themselves. The simulation model developed in that study assumes unlimited road capacity; the growth and decline of roads are reflected only by changes in their free-flow speeds. This presumption is relaxed in this study so that the impacts of network congestion on travel demand and supply can be incorporated in the analysis. Travel demand is represented by a more realistic user equilibrium pattern. In the network evolution process, links exhibit dynamics in both freeflow speed and capacity. The improved model is then applied to the Twin Cities transportation network with nearly 8,000 nodes and more than 20,000 links, which allows us to examine 
computational properties and predictive value of the proposed microscopic network dynamics model.

\subsection{Transportation Network Growth}

Few researchers have considered the process of transportation network growth at the microscopic level. Taaffe et al. (1963) studied the economic, political and social forces behind infrastructure expansion in underdeveloped countries. Their study found that initial roads are developed to connect regions of economic activity and lateral roads are built around these initial roads. A positive feedback between infrastructure supply and population also was observed. Barker and Robbins (1975) investigated the London Underground's growth, but did not develop a theoretical framework as we are considering here. Miyao (1981) developed macroscopic models to take transportation improvements as either an endogenous effect of urban economy or as an exogenous effect on the economy. Endogenous growth theory suggests that economic growth is a two-way interaction between the economy and technology; technological research transforms the economy that finances it (Aghion and Howitt 1998). The technology of transportation is unlikely to be an exception, suggesting transportation investment drives the growth that funds it. Macroscopically, infrastructure growth follows a logistic curve and road infrastructure also has reached saturation levels in developed countries (Grübler 1990). Miyagi (1998) proposed a Spatial Computable General Equilibrium (SCGE) model interacting with a transportation model to study the interaction of transportation and the economy. Yamins et al. (2003) developed a road growth model to study co-evolution of urban settlements and road systems from an empty space with highly simplified travel demand and road supply mechanisms meaningful only for 
theoretical works. Garrison and Marble (1965) observed that connections to the nearest large neighbor explained the sequence of rail network growth in Ireland.

Carruthers and Ulfarsson (2001) found that various public service expenditures like roadways are influenced by demographic and political characteristics. The New Jersey Office of State Planning (1996) also found a similar pattern in roadways expenditure. A related line of research examines how transportation investment affects the economy at large, but tends to treat transportation (or highways) as a black box(WHAT DOES THAT MEAN?) and makes no distinction between different kinds of highway investment (Aschauer 1989, Button 1998, Gramlich 1994, Nadiri and Mamuneas 1996). Boarnet (1997) is the most detailed of these types of studies and considers county roads. The input is investment in transportation (or infrastructure) and output is gross domestic product, measured at the state or county level. While this research provides no assistance in actually making tactical management decisions, it suggests a way that a strategic macroscopic network investment budget can be established.

Geography's central place theory seeks to explain how hierarchies of places develop (Christaller 1966). Models developed by Batty and Longley (1985), Krugman (1996), and Waddell (2001) consider land use dynamics, allowing central places to emerge. However, those models take the network as given. Clearly, there is a need for research that makes the network the object of study. In many respects, the hierarchy of roads is the network analogue of the central place theory.

\subsection{Models of Land Use Changes}

A number of land use change models have been developed to forecast development while considering transportation as an important influencing factor. One of the first that gained 
substantive interest was the Lowry model (Lowry, 1963). Several other model systems have adopted Lowry's methodology by examining basic, non-basic and service sectors sequentially, including DRAM, EMPAL, LUSDR, and MetroScope models. Land use models such as POLIS and TOPAZ rely on mathematical programming methods. Multisector input-output analysis has also been applied to land use modeling by incorporating spatial elements. Examples include MEPLAN and TRANUS. General equilibrium and computable general equilibrium land use models have also found applications (e.g., IUSMC and CSGE). More recently, advanced computing power has enabled the development of large-scale micro-simulation land use models such as MASTER, UrbanSim, TILUMIP2, and Markovian. Since the 1980s, many integrated land use models have been applied in real cities and some have been developed into commercial packages. Examples include START (Bates et al., 1991), LILT (Mackett 1991), and URBANSIM (Waddell 2002). Timmermans (2003) provides a comprehensive review of these land use models. In most of these models, the dynamics of urban space has been played out as the outcome of decisions made by residents and businesses, in which both accessibility to employment and accessibility to population play essential roles (Hansen, 1959; Guttenberg, 1960; Huff, 1963).

\subsection{Evolution of Urban Space}

The evolution of urban space has been examined by another stream(?) of studies. The pioneering work by von Thünen (1910) presented a monocentric city surrounded by agricultural land and predicted the rent and land use distribution for competing socio-economic groups. Christaller (1933) introduced central place theory and demonstrated that a hierarchy of central places will emerge on a homogenous plain to serve the surrounding market while minimizing transportation 
costs. Krugman (1996) explored the phenomenon of self-organization in urban space. He developed an edge city model to demonstrate how interdependent location decisions of businesses within a metropolitan area could lead to a polycentric pattern under the tension between centripetal and centrifugal forces.

Although the concept of accessibility connects transportation with land use development, the change of transportation networks has seldom been considered in previous land use models, and vice versa. A possible explanation is that these models are already complicated enough. They usually involve multiple modeling approaches, incorporate numerous constraints and assumptions, and are estimated from empirical data, unavoidably leading to a comprehensive modeling framework including a wide variety of components. In contrast to those complicated and all-encompassing models that do not provide an explicit perspective, this project models the integrated dynamics of land use and transportation in as simple a way as possible that captures salient properties. This enables us to display and analyze the emergent hierarchy and agglomeration patterns of space and network on a large scale. 


\section{THEORY: LAND USE AND TRANSPORTATION NETWORK DYNAMICS AT THE MICROSCOPIC LEVEL}

Regional economic growth is taken as exogenous for this study of land use and transportation network dynamics because land development and transportation infrastructure are not the only factors that drive economic growth. It has long been known that transportation service and land use influence each other though iterative changes in accessibility and travel demand. The dynamics of other factors such as travel behavior, link maintenance and expansion costs, network revenue, investment rules, link expansion and degeneration also are considered endogenously.

\subsection{The Dynamics of Transportation Network Growth}

The foremost and probably most important constraint on future network growth is the existing network. In developed countries where transportation infrastructure has reached saturation, it is rare to see new network growth from a tabula rasa. Even in an empty place without any previous development, natural barriers such as rivers and mountains still constrain future network growth. The current network connectivity determines whether two links complement (upstream or downstream) or compete (parallel) each other for demand. The existing network may or may not reach equilibrium. It may still take years for road supply to meet existing travel demand even if no exogenous changes (e.g., population and economic growth) occur. The important question is how various forces drive the existing network to evolve rather than how long it takes.

Based on the current network, land use arrangements and individual socio-economic status, people make travel decisions such as trip frequency, scheduling, destination, mode and 
route choices. These decisions transform into travel demand on the transportation network. This demand-generating process involves the existing network supply, congestion externalities, travel behavior, and link-level travel demand forecasting.

Transportation is a service and travelers pay to obtain that service in addition to spending their own travel time. In the U.S., that payment is largely in the form of a fuel tax. However, if links were autonomous, they would set prices to maximize their profits in the form of a vehicle toll. In many real-world transportation networks, government agencies collect fuel taxes as transportation revenue. We can set the price for using a link as a function of the link's length and level of service (LOS). It is convenient to use a notion of link revenue. Revenues collected by individual links may or may not be pooled together for investment purposes depending on the underlying institutional structure of the network. Longer, faster, and high-demand (traffic flow) links should be able to generate more revenue. If not maintained appropriately, link LOS will decrease over time due to physical deterioration caused by the environment and traffic. Therefore, each link has a maintenance cost function. Link length, capacity, free-flow speed, and flow determine maintenance cost to a large extent. The amount of money required to expand an existing link can be calculated with a link-expansion cost function. A previous empirical estimation of link expansion costs using network data in the Twin Cities during the past 20 years reveals that link expansion cost is positively correlated to lane-miles of expansion and road hierarchy (interstate, state highway, county highway, etc.), while negatively related to the distance from the nearest downtown (Levinson and Karamalaputi 2003). Those results suggest that link length and capacity should be included in the link-expansion cost function, and this function is also subject to local adjustments. 
Specific revenue and cost structures in a transportation network provide inputs for investment decisions. Real-world observation suggests the hypothesis that decisions to expand transportation networks are largely myopic in both time and space, usually ignoring nonimmediate and non-local effects. This myopic decision process, when applied sequentially, tends to improve the relative speeds and capacity of links that are already the most widely used, and thereby expand their use. The rate and extent of this process is constrained by the cost of those improvements and limited budgets (revenue). From a market economy point of view, transportation investment decisions induce supply (capacity) increases - as population grows and preferences shift, leading to higher demand, suppliers produce more of a particular good. While surface transportation decisions often are made in the political arena rather than the market, politicians and officials also respond to their customers - the voters and taxpayers. Over the short term, transportation supply is relatively inelastic; in the long run, it varies. However, it is not known to what extent changes in travel demand, population, income, and demography drive these long-run changes in supply. Answering this induced supply question in transportation is a critical step in understanding the long-term evolution of transportation networks. The output of the investment process would be an updated network where some links are expanded and others are degenerated.

If a link is expanded, travel increases on that link due to re-routing and re-scheduling and to what is often called induced or latent demand, a finding confirmed at both the macroscopic level (states and counties) (Noland 1998, Strathman et al. 2000, Fulton et al. 2000) and at the microscopic level (individual links) (Parthasarathi et al. 2002). As travel costs for commuters are lowered, the number of trips and their lengths increase. The expanded link with increased travel demand can generate even more revenue, which may later result in further expansion on 
that link. Yet this loop, while positive, should have limits. The diminishing returns in the revenue structure and exponential increases of expansion costs will eventually stop this feedback loop. The opposite is true for degenerated links. All these suggest that reinforcement exists and transportation networks may self-organize into hierarchies. This hypothesis is subject to simulation tests in the following section.

Improving one link also will cause greater demand on complementary (upstream and downstream) links, and lesser demand on competitors (parallel links), which are less likely to be improved. These network effects take time to propagate within transportation networks. They may get reinforced in complex transportation networks, create problems, leave little clue for planners as to the root of the problem, and force planners to adopt myopic solutions that may create even more problems. Such a condition has not been confirmed empirically but it is possible. This again highlights the importance of considering the full ramification of network expansion on future infrastructure decisions. Network effects both complicate the problem and suggest the analysis has to be iterative. Previous changes in the network, economy, demography, and even travel behavior cause a new travel demand pattern and, hence, new link costs and revenues. Accordingly, a new set of supply decisions will be made, generating new network changes. This loop is repeated until equilibrium is achieved. When the constant exogenous changes in economy, technology and population are considered, a transportation network may never reach equilibrium. The evolutionary microscopic network growth process should produce rich dynamics important to anyone who is interested in improving the future transportation network. 


\subsection{Integrated Land Use and Transportation Dynamics}

Land use changes in an urban area are driven by various forces and influenced by land development, rent/land price, location, regional economic growth, existing spatial distribution of activities, and transportation costs. Figure 3.1 summarizes the land use-transportation interaction at the macroscopic level. The network growth and other changes in the transportation system often causes transportation cost changes between origin-destination pairs, which results in changes in accessibilities to various locations such as jobs, houses and shopping. The ease or difficulty for residents to reach destinations and for businesses to reach suppliers/customers leads to location changes, and the relative desirableness of locations in the urban area. The land supply and land demand are equilibrated with a variety of price signals (e.g., land price, housing price, office/apartment rent). The re-allocated activities in turn imply a new travel demand pattern on the transportation network (the feedback to transportation). These aforementioned land use changes and transportation network changes often occur at dissimilar times, which adds to the difficulty of modeling this co-evolution process.

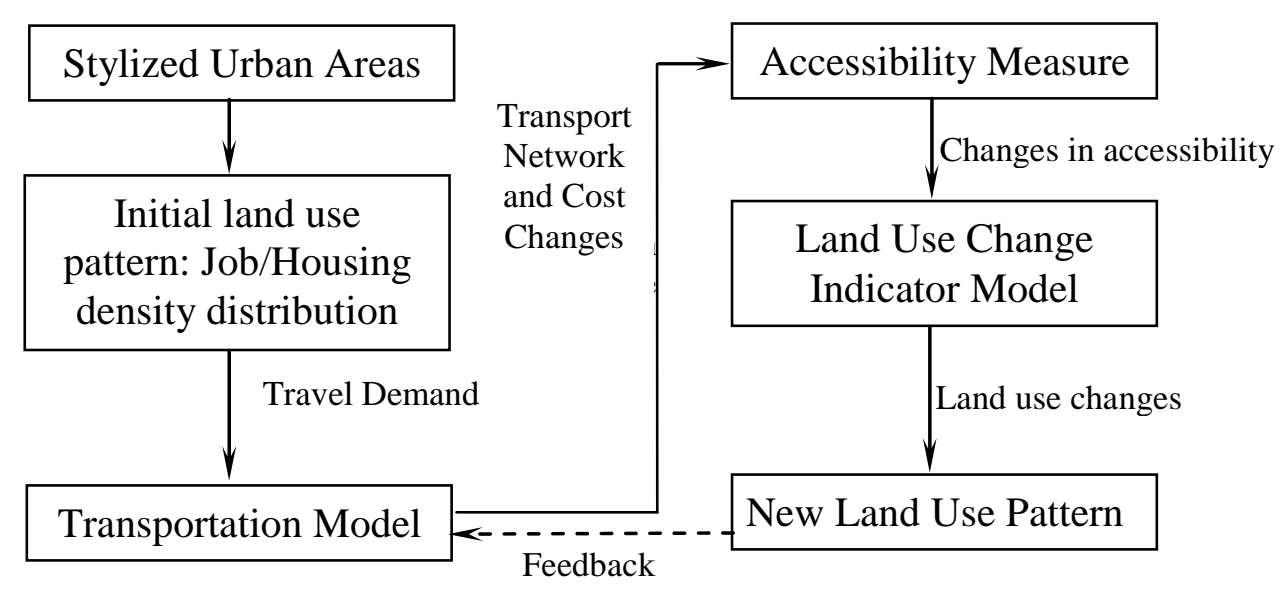

Figure 3.1. Land Use-Transportation Integration 
At a slightly more microscopic level, the feedback relationship between transportation and land use variables within an urban system can be illustrated in a co-evolution process (see Figure 3.2). An arrow with a plus (+) or minus (-) between two boxes shows a positive or negative relationship between the boxes. As can be seen, road expansion increases capacity, which improves free flow speed; the increased capacity increases cost, then forces the capacity back according to the investment rules. The improvement in travel time increases traffic flow, which increases revenue and facilitates road expansion. The improvement of travel time also increases both accessibility to jobs and houses. Employment density is positively associated with both accessibilities while population density is negatively impacted by accessibility to houses. Increased employment or population density increases intra-zonal travel time, which offsets the improvement of travel time due to road investment. After investing (or disinvesting) in each link in the network, computing accessibility, and relocating land uses, the time period is incremented and the whole process is repeated.

The most detailed land use analysis requires the consideration of each land use decisionmaker. That is the impact of transportation network changes on land use decisions andrepresents the collective locational behavior changes at the household and individual business level. Although it is possible to conduct land use change analysis at this completely microscopic level, this project focuses on land use dynamics as measured by accessibilities and density changes in a number of aggregate urban zones. 


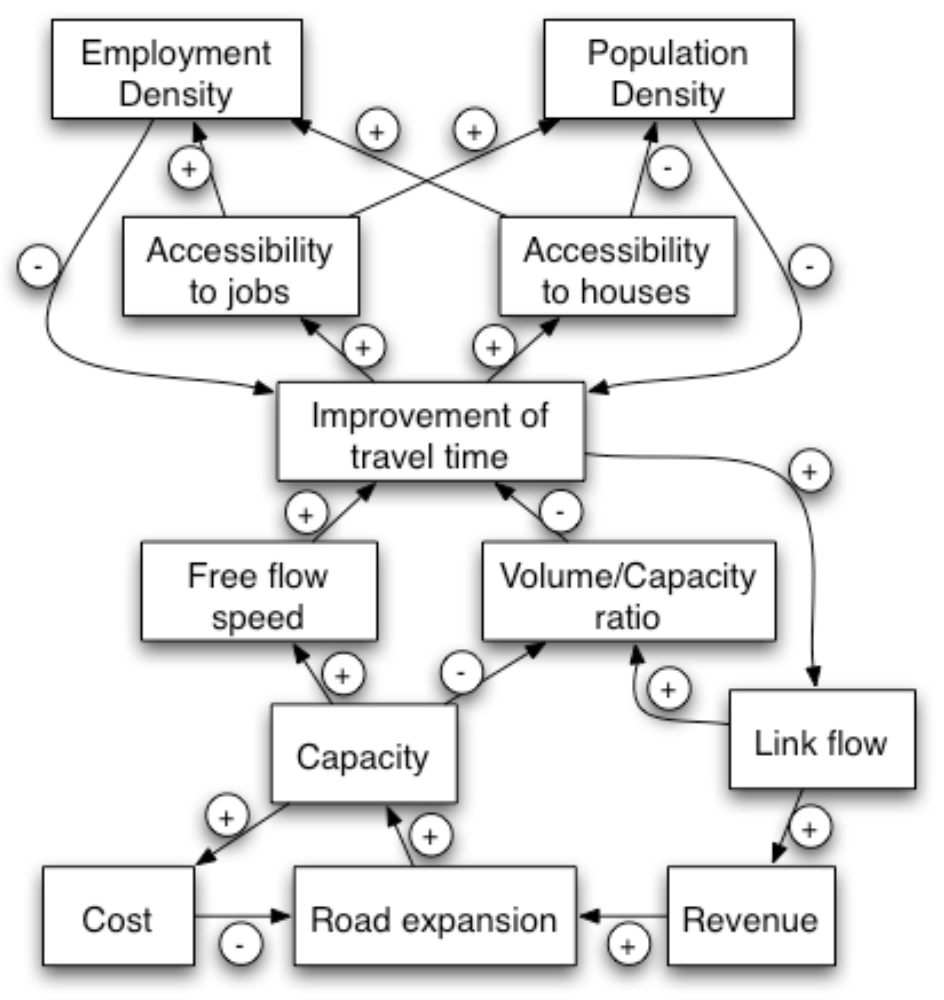

Figure 3.2. Feedbacks in a Co-Evolving Land Use-Transportation System 


\section{MODELING TRANSPORTATION NETWORK GROWTH}

In this research, an improved network growth model is developed that brings together all the relevant agents and their interactions to simulate road expansion and contraction. Compared to the earlier network dynamics model (Yerra and Levinson 2002), this improved model relaxes the assumption of unlimited link capacity, a necessary step that has to be taken to make the model of any practical importance. The foundation for the model development is the microscopic network growth dynamics described in the previous section. The simulation model can be used to evaluate whether or not important system properties such as hierarchy, self-organization and growth actually emerge from decentralized processes. This purpose makes the principles of and modeling techniques for complex systems applicable. There is no universally accepted definition of a complex system. However, it is generally agreed that it consist of "a large number of components or 'agents,' interacting in some way such that their collective behavior is not a simple combination of their individual behavior" (Newman 2001), which is the case in transportation networks. Examples of complex systems include the economy - agents are competing firms; cities - places are agents; traffic - vehicles are agents; ecology - species are agents. In transportation networks, we model nodes, links, travelers and land use cells as agents. Cellular Automata (CA) and agent-based modeling techniques are commonly employed tools for modeling complex systems (von Neumann 1966; Schelling 1969; Wolfram 1994, 2002). An agent-based structure is used in the proposed network dynamics model. An overview of model components and their interconnectivity is shown in Figure 4.1.

A travel demand model predicts link-level flows based on the network, socio-economic and demographic information. Based on the demand forecasting results, links calculate revenues and costs. An investment module then operates and causes annual supply changes, producing an 
updated network. The modeling process does not have to iterate annually. Other updating intervals also can be used, but yearly supply changes correspond to budgets which are typically decided each fiscal year. The transportation network is represented as a directed graph that connects nodes with directional arcs (links). The standard notation convention for directed graphs is adopted for the following presentation on the details of mathematical formulations of those sub-models. The directed graph is defined as: $G=\{N, A\}$ where $N$ is a set of sequentially numbered nodes and $A$ is a set of sequentially numbered directed arcs.

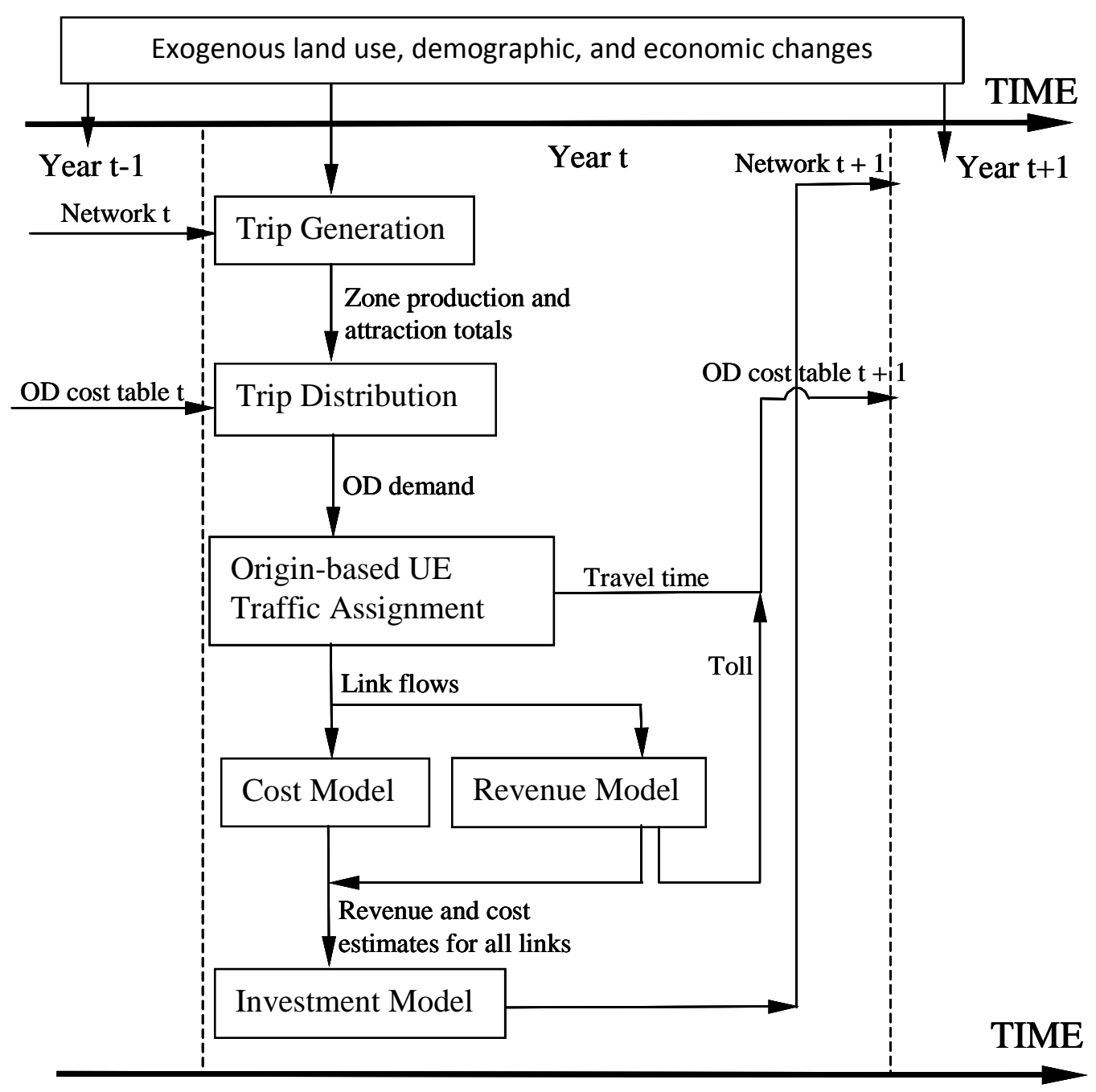

Figure 4.1. Flowchart of the Transportation Network Growth Model 


\subsection{Travel Demand}

Ideally, an agent-based travel demand model in which node, link and travelers are modeled as interactive agents should be applied to estimate travel demand at the level of links, so as to keep the disaggregate model structure consistent. A previous study (Zhang and Levinson 2003) has proposed such a model with successful application to the Chicago sketch network. However, for two reasons it is not adopted here. First, in its current form, the agent-based travel demand model is not capable of incorporating congestion effects. The second and probably more important reason is that most urban planners currently do not use disaggregate approaches to predict future travel demand in their daily practices. Therefore, a traditional four-step forecasting model is used to predict travel demand at the link level, taking exogenous land use, social-economical variables and the existing network as inputs. A zone-based regression structure is used for trip generation. The origin-destination (OD) cost table obtained from the previous year traffic assignment is used for trip distribution in the current year based on a doubly constrained gravity model (Haynes and Fotheringham 1984, Hutchinson 1974). The computation of the new OD demand table takes into account the historical impacts of past travel behavior. Travel demand in a given year depends on the demand in the previous year. Levinson (1995) elaborates the idea of such a hybrid evolutionary model. In contrast to a traditional equilibrium model, the evolutionary demand updating procedure does not require supply and demand to be solved simultaneously. In this study, the new OD demand is updated by a process similar to the method of successive averages (MSA) (Sheffi 1985, Smock 1962) in traditional traffic assignment procedures. The weights in equation (4.1) are specified in such a way that OD demand tables in all preceding years are weighted equally toward the current year (i) OD demand. 


$$
q_{r s}^{i}=\left(1-\frac{1}{i}\right) q_{r s}^{i-1}+\left(\frac{1}{i}\right) m_{r} O_{r} n_{s} D_{s} \cdot d\left(t_{r s}^{i}\right)
$$

where:

$$
\begin{aligned}
& q_{r s}{ }^{i} \quad \text { demand from origin zone } r \text { to destination zone } s \text { in year } i \\
& O_{r} \quad \text { number of trips produced from zone } r \\
& D_{s} \quad \text { number of trips destined for zone } s \\
& m_{r}, n_{s} \quad \text { coefficients in the gravity model } \\
& t_{r s}^{i} \quad \text { generalized travel cost of traveling from zone } r \text { to } s \\
& d(.) \quad \text { travel cost impedance function in the gravity model; } d\left(t_{r s}^{i}\right)=e^{-\gamma \cdot t_{r s}^{i}} \\
& \gamma \quad \text { coefficient in the impedance function }
\end{aligned}
$$

The resulting OD table is loaded onto the current year transportation network through the originbased user equilibrium traffic assignment algorithm (OBA) developed by Bar-Gera and Boyce (2002). The generalized link cost function comprises two parts, a BPR travel time component and a vehicle toll.

$$
t_{a}^{i}=\lambda \frac{l_{a}}{v_{a}^{i}}\left[1+\theta_{1}\left(f_{a}^{i} / F_{a}^{i}\right)^{\theta_{2}}\right]+\tau_{a}^{i}
$$

where:

$$
\begin{array}{ll}
t_{a}{ }^{i} & \text { generalized travel cost on link } a \text { in year } i \\
\lambda & \text { value of travel time constant (dollar/hr) } \\
v_{a}{ }^{i} & \text { free-flow speed of link } a(\mathrm{~km} / \mathrm{hr}) \text { in year } i \\
F_{a}{ }^{i} & \text { capacity of link } a \text { in year } i(\mathrm{veh} / \mathrm{hr}) \\
l_{a} & \text { the length of link } a \text { (constant) }(\mathrm{km})
\end{array}
$$


$f_{a}^{i} \quad$ average hourly flow on link $a$ in year $i(\mathrm{veh} / \mathrm{hr})$

$\theta_{1}, \theta_{2}$ coefficients of the BPR travel time function

$\tau_{a}^{i} \quad$ link toll per vehicle (dollar, see equation 4 for details)

The OBA algorithm derives link flows at user equilibrium and generates a new OD cost table, which will be used for trip distribution in the next year. In the traffic assignment step, if the relative excess travel cost is less than 0.001, the Wardrop user equilibrium (Wardrop 1952) is considered to be satisfied.

\subsection{Revenue and Cost}

Revenue is collected at the link level by vehicle toll. The annual revenue is simply the product of the toll and annual flow. The amount of the toll should depend on the length of the link and the level of service. Therefore, the following revenue equation is proposed:

$$
\begin{aligned}
& E_{a}^{i}=\tau_{a}^{i} \cdot\left(\psi \cdot f_{a}^{i}\right) \\
& \tau_{a}^{i}=\rho_{1} \cdot\left(l_{a}\right)^{\rho_{2}} \cdot\left(v_{a}^{i}\right)^{\rho_{3}}
\end{aligned}
$$

where:

$$
\begin{aligned}
& E_{a}{ }^{i} \quad \text { revenue (earnings) of link } a \text { in year } i \text { (dollar) } \\
& \psi \quad \text { coefficient to scale average hourly flow to annual flow } \\
& \rho_{1} \quad \text { scale coefficient related to the toll level (dollar } \cdot \mathrm{hr}^{\rho 3} / \mathrm{km}^{\rho 2+\rho 3} \text { ) } \\
& \rho_{2}, \rho_{3} \quad \text { coefficients indicating economies or diseconomies of scale }
\end{aligned}
$$

As the free-flow speed of a link increases, travelers are able to save travel time and, hence, are willing to pay a higher toll. However, speed improvements have decreasing returns. For instance, 
if speed triples from 8 to $24 \mathrm{~km} / \mathrm{hr}$, time spent traveling one kilometer drops 5 minutes from 7.5 min to $2.5 \mathrm{~min}$. If speed increases $16 \mathrm{~km} / \mathrm{hr}$ from $88 \mathrm{~km} / \mathrm{hr}$ to $104 \mathrm{~km} / \mathrm{hr}$, the time drops from 41 seconds to 35 seconds - merely 6 seconds - which hardly seems worth considering. Therefore, coefficient $\rho_{3}$ should be between 0 and 1 . Note that with appropriate values for those coefficients, the toll-based link-level revenue structure can also reasonably model centralized revenue collection mechanisms, such as fuel taxes ( $\rho_{2}=1$ and $\rho_{3}=0$ ).

The link-maintenance cost function has only two determining factors: link length and capacity:

$$
C_{a}^{i}=\mu \cdot\left(l_{a}\right)^{\alpha_{1}}\left(F_{a}^{i}\right)^{\alpha_{2}}
$$

where

$$
\begin{aligned}
& C_{a}^{i} \quad \text { cost of maintaining link } a \text { at its present condition in year } i \text { (dollar) } \\
& \mu \quad \text { scale parameter (dollar } \cdot \mathrm{hr}^{\alpha 2} / \mathrm{km}^{\alpha 1} \text { ) } \\
& \alpha_{1}, \alpha_{2} \text { coefficients indicating economies or diseconomies of scale }
\end{aligned}
$$

It is also assumed that all links have the same link-maintenance cost function. This assumption is obviously not realistic and should be relaxed when local link-specific data are available.

The link-expansion cost function is not explicitly specified. If a link is autonomous and its annual revenue is higher than maintenance costs, the link will be expanded in the next year, assuming revenue is not spent elsewhere. If revenue falls below maintenance costs, the link shrinks in terms of capacity reduction and free-flow speed drop. As we will see later in the investment model, those ideas are actually incorporated into a link expansion/contraction function. 


\subsection{Investment Rules}

The sub-model of network investment decisions can have two aims: describe reality or identify optimal policies. The emphasis in this paper is the prior one, which is in contrast to the long line of research on the Network Design Problem. The network dynamics model must be able to replicate what has happened in reality before it is applied for potential planning purposes. A prototype investment rule (link expansion and contraction function) is examined in which links manage themselves and do not share revenues.

$$
F_{a}^{i+1}=F_{a}^{i}\left(E_{a}^{i} / C_{a}^{i}\right)^{\beta}
$$

where $\beta \quad$ capacity change coefficient

Note that investment decisions in equation (4.6) are very myopic ones in that links only care about themselves, ignore network effects and spend all revenues immediately (This sentence gives links human abilities - consider rewording the second half). The value of $\beta$ actually represents some properties of the link expansion process. If $\beta$ is less than 1 , it implies that there are diseconomies of scale in link expansion because doubled investment $(E)$ would only produce less than doubled capacity. If $\beta$ is larger than 1 , economies of scale exist. Capacity changes of a link are usually associated with changes in free-flow speed. Vehicles are able to travel at faster speeds on a wider road with less impedance. Free-flow speed and capacity data used by the Twin Cities Metropolitan Council in its regional transportation planning model on more than 10,000 roadway sections were used to study the correlation of speed and capacity. A log-linear model is adopted (see Figure 4.2). $R^{2}$ of the model is 0.7 and both coefficients are statistically significant at level 0.01 . 


$$
v_{a}^{i+1}=\omega_{1}+\omega_{2} \cdot \ln \left(F_{a}^{i+1}\right)
$$

The predicted free-flow speeds are plotted against data in Figure 4.2. Keeping component functions such as this one continuous and differentiable in the network dynamics model can save a lot of work for the calibration stage. This is also the reason why an explicit link expansion cost function is not specified and why it is assumed that (links invest any extra revenue immediately see above recommendation). However, if these simple continuous functions cannot adequately replicate reality, more sophisticated modeling tools should be considered. For instance, link expansion and contraction are in fact discrete events for which a choice model or catastrophe theory may be applied. With updated link capacity and free-flow speed, some factors influencing travel behavior, such as link travel time and link toll, change. Theses supply shifts, combined with preference, economical growth and demographical changes, give rise to the emergence of a

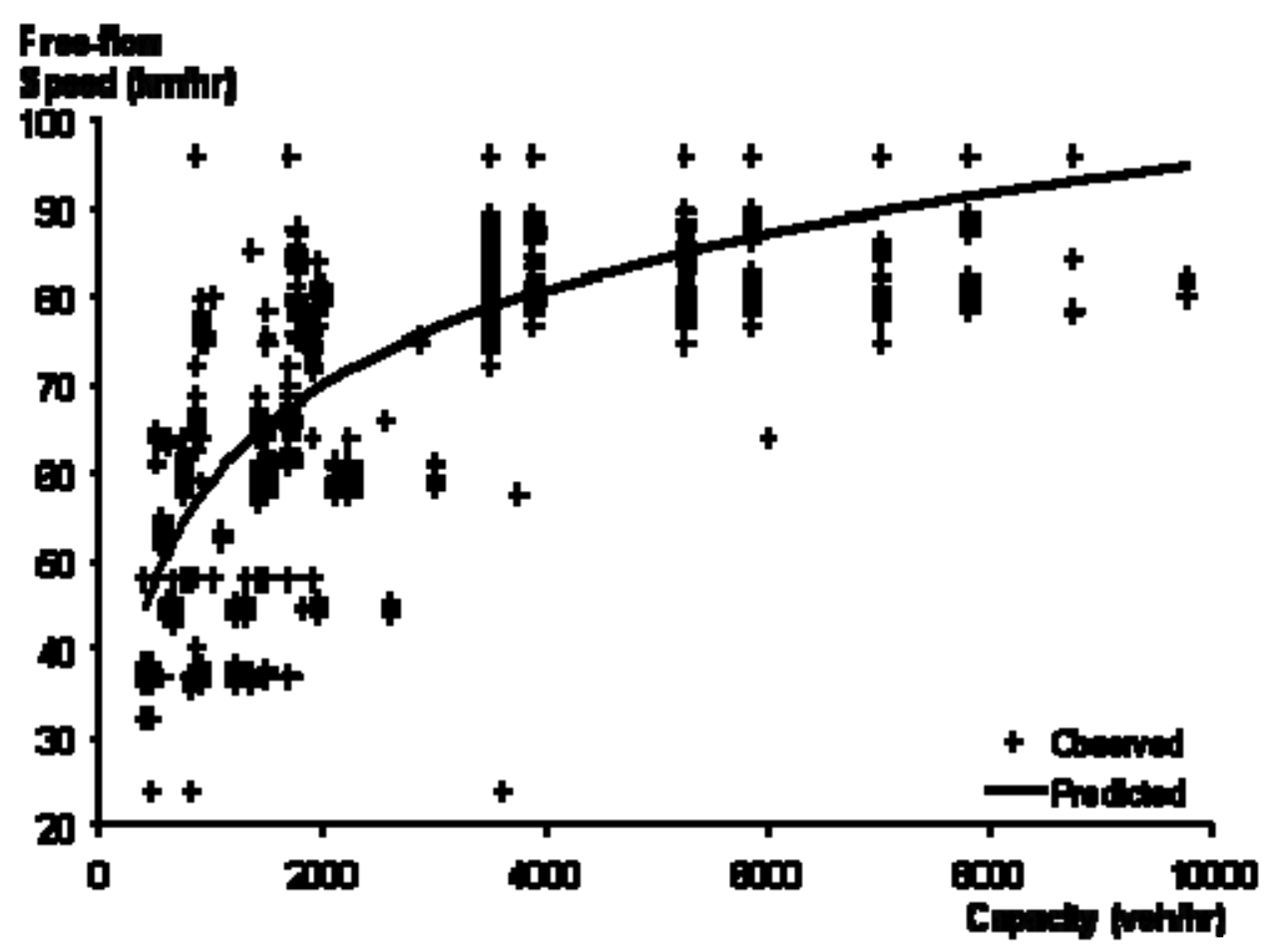

Figure 4.2. Link Capacity and Free-Flow Speed Relationship: Observed (from regional transportation planning model) versus Predicted (log-linear regression model) 
new demand pattern.

\subsection{Discussion on Model Calibration and Validation}

So far, a complete cycle of the network evolution process has been modeled. This cycle repeats itself year after year. Simulation of these cycles can reveal various emergent properties of transportation network growth. The proposed transportation network growth model can and should be calibrated and validated against observed time-series network and land use data. The calibration procedure may consist of two stages. The parameters in the sub-models (demand, revenue, cost, and investment) are estimated from empirical network data. These estimates then form a starting solution for an iterative optimization routine with an improving search algorithm. Finer adjustments to the model system and parameters should be undertaken based on an objective function, which can minimize the difference between the observed data and the model ability to predict which links were improved and by how much. In brief, the model parameters form a space which can be searched systematically to find a best fit between actual and predicted link expansions and contractions. For instance, the transportation network data in the Twin Cities metro area have been collected between 1978 and the present in digital format, while data collection work on corresponding land use and economical information is ongoing. In the most recent (2000) Twin Cities transportation planning network, there are 7,976 nodes and 20,914 links. A bit more than 600 link expansions have taken place since 1978, which implies the Twin Cites transportation network is mature. 


\section{MODELING LAND USE CHANGES}

\subsection{Accessibility Measures}

Accessibility is the product of a temporal element reflecting travel costs (e.g., the impedance function from gravity models applied to the travel time between two zones) and a spatial element reflecting the distribution of the activities in a region (for instance, number of jobs or houses) (Burns 1979, Hanson 2004). It measures the available activities, such as job opportunities, that can be reached within a certain amount of commuting time or the ease of reaching destinations. Accessibility is just one of the various factors that affect urban spatial patterns. Several previous studies conclude that accessibility has ambiguous influences on employment and residential distributions in a region (Adams 1999), while others suggest that accessibility changes significantly affect location choices (Payne-Maxie Consultants 1980). Nevertheless, the fact that

urban regions do not extend infinitely over space indicates that commuting time and accessibility are significant factors. The fact that the actual commute exceeds the minimum required commute (however defined) indicates that accessibility is not the only factor.

We adopt two standard measures of job and residential accessibility to convert travel time changes into accessibility shifts. The impedance function is drawn from a previously estimated gravity model for work-trip distribution in the Twin Cities.

$$
\begin{aligned}
& A_{i, E}=\sum_{j}\left[E_{j} f\left(t_{i j}\right)\right] \\
& A_{i, P}=\sum_{j}\left[P_{j} f\left(t_{i j}\right)\right] \\
& f\left(t_{i j}\right)=\exp \left(a+b t_{i j}\right)=\exp \left(-0.97-0.08 t_{i j}\right)
\end{aligned}
$$

Where:

$A_{i, E}: \quad$ Accessibility to jobs (employment) from zone $i$ 
$A_{i, P}: \quad$ Accessibility to houses (residence) from zone $i$

$E_{j}: \quad$ Number of jobs (employment) in zone $j$

$P_{j}: \quad$ Number of houses (residence) in zone $j$

$f\left(t_{i j}\right)$ : Impedance function of travel time between zones $i$ and $j$

$t_{i j}: \quad$ Peak-hour auto travel time from zones $i$ to zone $j$

With the number of zonal opportunities such as jobs and houses in the definition, these two accessibility measures determine the likelihood that a job (house) would be filled by a person according to how easy the person can reach it. Similar accessibility measures were used in many previous studies (Handy 1993, Hanson 1987, Levinson 1998, Williams 1989, among others).

\subsection{A Modified Land Use Change Indicator Model}

The original land use change indicator model (LUCI) assumes the availability of the base year population and employment data (Roberts and Simmonds 1997). Another model input is the accessibility in the transportation network in both the base year and the forecast year. The LUCI model is a simplified version (without market segmentation) of the regional growth allocation models used by many MPOs. The model has a logit(?) functional form as follows:

Population (Housing) Redistribution:

$$
P_{i}^{2}=P \frac{P_{i}^{1} \exp \left[b\left(A_{i, E}^{2}-A_{i, E}^{1}\right)\right)}{\sum_{i} P_{i}^{1} \exp \left[b\left(A_{i, E}^{2}-A_{i, E}^{1}\right)\right)}
$$

P: $\quad$ The fixed total study area population

$P_{i}^{2}: \quad \quad$ New zonal population resulting from an accessibility change 
$P_{i}{ }^{l}: \quad$ The initial population of zone $i$

$b$ : $\quad$ The calibrated sensitivity coefficient in the accessibility measure

$A^{2}{ }_{i, E}$ : The new accessibility to work of zone $i$

$A^{1}{ }_{i, E}$ : The initial accessibility to work of zone $i$

Employment Redistribution:

$$
E_{i}^{2}=E \frac{E_{i}^{1} \exp \left(A_{i, P}^{2} / A_{i, P}^{1}\right)^{b}}{\sum_{i} E_{i}^{1} \exp \left(A_{i, P}^{2} / A_{i, P}^{1}\right)^{b}}
$$

E: $\quad$ The fixed total study area employment

$E_{i}^{2}$ : $\quad$ New zonal employment resulting from an accessibility change

$E_{i}^{1}$ : The initial employment of zone $i$

$A^{2}{ }_{i, P}$ : $\quad$ The new accessibility to house of zone $i$

$A^{1}{ }_{i, P}$ : The initial accessibility to house of zone $i$

LUCI is an empirical spatial interaction model. An interpretation of the model is that due to changing travel costs between origins and destinations, jobs and houses located in a specific zone may become more (or less) accessible relative to other zones in the region, which leads to an increased (or decreased) level of future jobs and houses in that zone. The total regional employment and housing units are kept constant. Therefore, LUCI is strictly a land use redistribution model and not a growth model. The extent of the land use redistribution process depends on the calibrated coefficient $b$ in the travel-time impedance function, which can be interpreted as users’ willingness to travel further for better activity locations. 
Accessibility in the original LUCI model is simply defined as a travel-time decay function without considering activity opportunities at various destination zones. In order to adopt the more reasonable accessibility measures in Equations (3) and (4), the model structure needs to be modified. The modified model for residential redistribution is:

$$
P_{i}^{2}=P \frac{P_{i}^{1} \exp \left[\frac{b}{\bar{E}}\left(A_{i, E}^{2}-A_{i, E}^{1}\right)\right]}{\sum_{i} P_{i}^{1} \exp \left[\frac{b}{\bar{E}}\left(A_{i, E}^{2}-A_{i, E}^{1}\right)\right]}
$$

$\bar{E}$ : Average zonal employment of the study area

The sensibility of land use to accessibility changes is now $b / \bar{E}$ instead of $b$ in the original model. Since the employment model has a fractional form relating the accessibility in the base year to that in the forecast year, no modifications are required. Equations (5.1) and (5.6) constitute the modified land use change indicator model. 


\section{A MODEL OF LAND USE - TRANSPORTATION CO-EVOLUTION}

The transportation network growth and land use change models are developed in Sections 4 and 5, respectively. In order to integrate these two models into a consistent co-evolution model of land use and transportation, we need to address several important modeling issues, including simulation time scales, determination of coefficient values, and computer implementation.

The evolutionary process in the land use-transportation system is driven by the decisions of individuals, households, businesses, developers, and regulators. These decisions are often made on different time scales. For instance, travel behavior such as destination, departure time, model, and route choices can change overnight. Pricing, taxation, and infrastructure investment decisions take longer and are usually annual or biannual decisions. Location choices respond to transportation network capacity and cost changes in the long run, and may take decades to change. In the prototype model, it is assumed that all decisions are annual decisions and that, in each year, the land use-transportation system achieves a short-run equilibrium wherein travel demand, transportation costs, and location choices are equilibrated. The integrated co-evolution model of land use and transportation under this assumption is illustrated in Figure 6.1. As a transportation network grows over time, a series of short-run equilibria will be observed until a long-run urban growth equilibrium is reached. At the urban growth equilibrium, there is no incentive for transportation users to unilaterally change travel behavior, for transportation authority to unilaterally expand or denigrate the transportation network, and for households or firms to unilaterally change their land use decisions. In this co-evolution model, transportation network growth causes land use changes, which results in new travel demand patterns, produces new demand for infrastructure, and, in turn, affects future network growth. Land use and the transportation network, therefore, co-evolve until the long-run urban growth equilibrium is 
achieved. This equilibrium concept reflects a central tendency and is useful for land use and transportation policy evaluation, while in reality it may never be achieved due to continuous exogenous changes in regional population and economy.

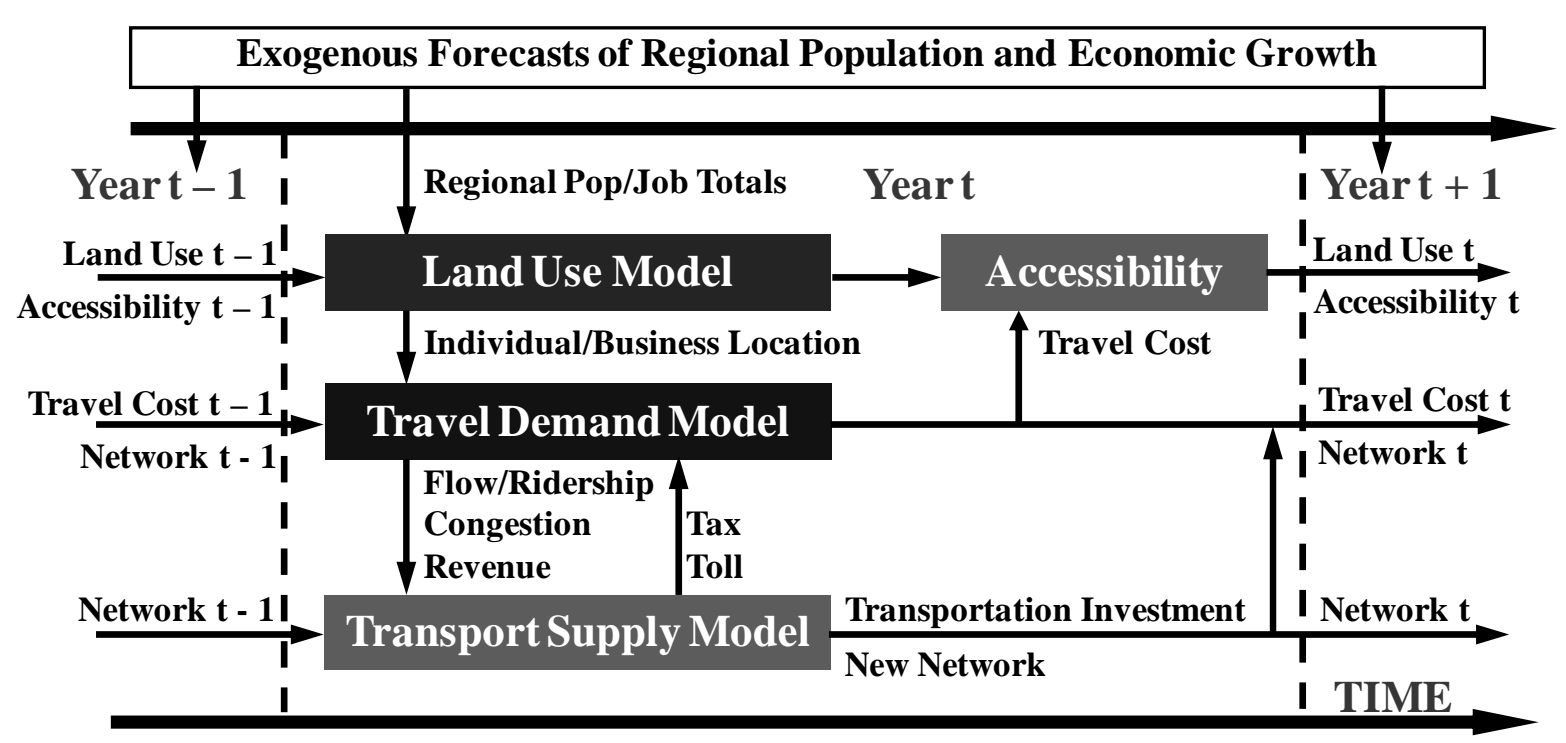

Figure 6.1. A Co-Evolution Model of Land Use and Transportation

Although a rigorous calibration and validation of all coefficients in the transportation network growth and land use change models are beyond the scope of this exploratory research project, simulating the co-evolution model in contrived or real-world urban systems can still provide valuable information regarding the modeling concept, structure, and feasibility for real-world applications. The values of the model parameters are currently determined from either empirical estimation using the Twin Cities dataset (network growth data from 1978-1998 and the existing four-step travel demand model), or our best understanding of the economies and diseconomies of scale in the network growth process. These preliminary model coefficient estimates are summarized in Table 6.1. 
Table 6.1. Coefficients in the Co-Evolution Model of Land Use and Transportation

\begin{tabular}{|c|c|c|c|}
\hline Parameter & Description & Value & Source \\
\hline$\lambda$ & value of travel time constant $(\$ / \mathrm{hr})$ & 10 & Empirical findings \\
\hline$\theta_{1}, \theta_{2}$ & coefficients in the BPR function & $0.15,4$ & BPR \\
\hline$\gamma$ & coefficient in the gravity model & 0.1 & Empirical findings \\
\hline$\rho_{l} \cdot \psi$ & $\begin{array}{l}\text { Combined scale coefficient in revenue } \\
\text { model (dollar } \cdot \mathrm{hr}^{\rho 3} / \mathrm{km}^{\rho 2+\rho 3} \text { ) }\end{array}$ & 1 & Scale parameter \\
\hline$\rho_{2}$ & Power term of length in revenue model & 1 & CRS of link length \\
\hline$\rho_{3}$ & Power term of speed in revenue model & 0.75 & DRS of level of service \\
\hline$\mu$ & $\begin{array}{l}\text { Scale coefficient in cost model } \\
\left(\text { dollar } \cdot \mathrm{hr}^{\alpha 2} / \mathrm{km}^{\alpha 1}\right)\end{array}$ & 20 & Scale parameter \\
\hline$\alpha_{1}$ & Power term of length in cost model & 1 & CRS of link length \\
\hline$\alpha_{2}$ & Power term of capacity in cost model & 1.25 & IRS of capacity \\
\hline$\omega_{1}, \omega_{2}$ & $\begin{array}{l}\text { coefficient in the speed-capacity log- } \\
\text { linear regression model }\end{array}$ & $-30.6,9.8$ & $\begin{array}{l}\text { Empirical estimate based } \\
\text { on Twin Cities data }\end{array}$ \\
\hline$\beta$ & capacity change coefficient & 0.75 & DRS in link expansion \\
\hline$b$ & $\begin{array}{l}\text { Accessibility measure and land use } \\
\text { change coefficient }\end{array}$ & -0.08 & Empirical findings \\
\hline
\end{tabular}

CRS, DRS and IRS: constant, decreasing, and increasing returns to scale

These land use change model is originally developed in Python and R-codes, while the transportation network growth model is implemented in Java. A common computer programming platform needs to be identified for computer applications of the co-evolution 
model. Java is selected as the preferred computer programming language for its objectiveoriented structure for easy future extensions and its superior capability for online applications. 


\section{DEMONSTRATION OF THE CO-EVOLUTION MODEL}

The co-evolution model of land use and transportation is demonstrated in two test scenarios. This first test applies the model to a hypothetical urban area with uniform initial land use patterns and a grid road network. The second test is conducted on the actual road network in the Twin Cities. These tests reveal some interesting relationships between land use changes and transportation network growth, and improve our understanding of urban system dynamics. It is also (who?) that the proposed methodology is appropriate for large-scale applications.

\subsection{The Land Use and Transportation System Growth in a Hypothetical City}

The first graph (Year 0) in Figure 7.1 illustrates the initial land use and transportation network conditions in a hypothetical city used in our first test of the co-evolution model. The city has a 15 by 15 grid road network in the starting year. Each roadway link is one-mile long and has an initial capacity of 735 vehicles/hour. The urban area is also divided into 22,500 (150 by 150) land use cells, with each cell measuring 0.1 by 0.1 mile. A uniform initial land use pattern is assumed, and each cell has 100 residents and 100 jobs (i.e., 2.25 million total population and total jobs). In the first experiment, the co-evolution model is applied with transportation network changes only. The second experiment allows both land use and transportation system changes. This comparison will enable us to analyze the consequence of ignoring land use in the study of network evolution.

Figure 7.1 presents the transportation network changes predicted by the co-evolution model. The color of roadway links represents the capacity, with green representing the lowest capacity category and red indicating the highest capacity category. Two very distinctive growth paths can be observed while this hypothetical city reaches the final urban growth equilibrium 
(UGE) in the two experiments. The UGE is achieved when no significant land use or transportation network changes are predicted in five consecutive years. Experiment 1 reached equilibrium after 38 iterations (years) and Experiment 2 after 56 iterations. In both simulation experiments, one can observe the emergence of major north-south and east-west corridors and major beltway corridors. When the land use pattern is fixed (i.e., no location changes by households or firms) the distribution of transportation network capacity is more even across the urban area because travel demand is distributed more evenly in this case. When location changes are considered in Experiment 2, we can clearly see the emergence of a strong urban core in the center of the city. Households and firms want to locate in the city center because of its superior accessibility to jobs and houses. Another important observation is that the total amount of transportation network capacity expansion is significantly less in Experiment 2, which implies lower overall transportation investment in this scenario. Improved flexibility in location choices results in less systemwide demand for transportation infrastructure, according to these simulation findings.

Figure 7.2 illustrates the land use changes over time in Experiment 2, which is measured by a Gini Coefficient. The coefficient reflects the unevenness in the job and housing distributions among all land use cells. It ranges from 0 to 1, with 0 indicating complete inequity (i.e., one land use cell has all the jobs or all the houses), and 1 indicating perfect equity (all land use cells have the same amount of jobs and houses). The equations for computing the Gini Coefficients are available in Equations 7.1 and 7.2.

$$
G_{H}=\frac{\sum_{m=1}^{q} \sum_{n=1}^{q}\left|H_{m}-H_{n}\right|}{2 q \sum_{m=1}^{q} H_{m}}
$$




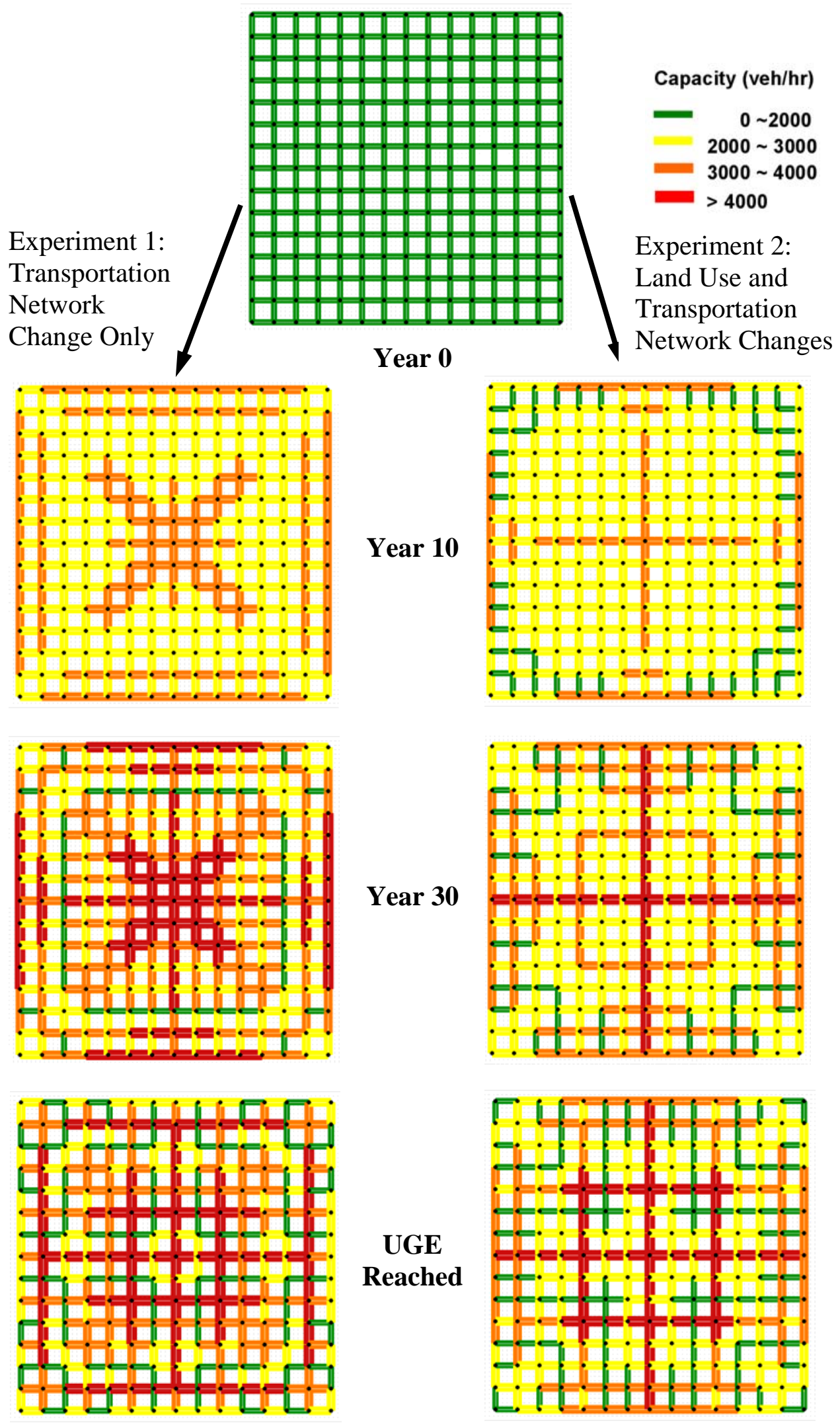

Figure 7.1. Evolution of the Hypothetical City 


$$
G_{J}=\frac{\sum_{m=1}^{q} \sum_{n=1}^{q}\left|J_{m}-J_{n}\right|}{2 q \sum_{m=1}^{q} J_{m}}
$$

Where:

$G_{H} \quad$ Gini Coefficient of residential distribution (House Gini);

$G_{J} \quad$ Gini Coefficient of job distribution (Job Gini)

$H \quad$ Number of residents located in a particular land use cell

$J \quad$ Number of jobs located in a particular land use cell

$m, n \quad$ Indices of land use cells

$q \quad$ Total number of land use cells

The continuous reduction in the values of the house and job Gini Coefficients shows that residents and jobs are relocated through the simulation process, and that the land use cells that are able to attract more activities in the first several years also will attract more activities in later years. Eventually, the trend of increasing concentration in residential and employment land use patterns stops as the city approaches urban growth equilibrium due to congestion effects and the increasing costs of adding transportation capacity to the congested areas. We can also observe a higher degree of concentration of employment, which result in the emergence of major employment centers in the city center and several smaller employment centers near the first beltway system (see Figure 7.1, the first red ring). 


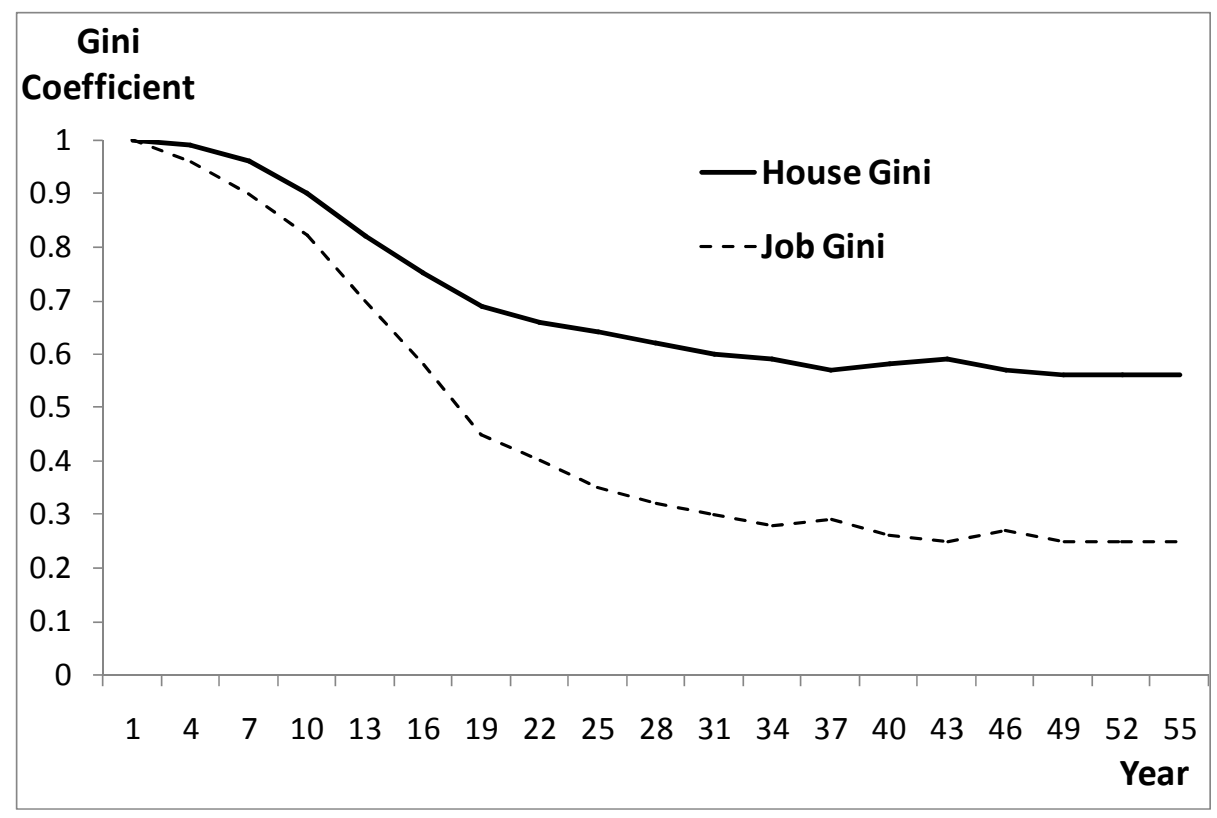

Figure 7.2. Land Use Changes Over Time in Experiment 2

\subsection{A Large-Scale Application in the Twin Cities Metropolitan Area}

In this section, we apply the co-evolution model to the Twin Cities metro area to demonstrate its capability for large-scale implementations. Because some coefficients in the model are not yet empirically calibrated or validated, the purpose of this section is certainly not to claim the readiness of the co-evolution model for real-world land use-transportation policy analysis. It only demonstrates the methodology in a large land use-transportation system.

Four experiments are set up with different initial conditions and restrictions on land use dynamics (see Table 7.1). It is assumed in all experiments that there are no exogenous changes in regional economy and population. The initial land use, economy, population, and transportation network in the model are based on 1978 Twin Cities Metropolitan Council data. These four experiments simulate land use and transportation evolution in the area between 1978 and 1998. Using the real 1978 network as the initial condition for the simulation model (Experiments 1 and 
2) allows us to observe whether and how this real-world network achieves long-term urban growth equilibrium. Experiment 2 also allows land use changes, while land use is fixed in Experiment 1. The real 1978 network already exhibits hierarchy in that a few important roads carry the bulk of traffic while most roads have relatively low speed and volume. In order to see how network hierarchy emerges in the growth path, the other initial condition is the 1978 network with a uniform capacity of 400 vehicles/hour, which is the capacity of the narrowest link in the 1978 network. The adoption of these two different initial scenarios can also reveal whether starting conditions significantly affect the future growth of a land use-transportation system. In Experiment 3 land use changes are assumed away, while land use changes are simulated in Experiment 4. In these simulation experiments, if the network and land use do not change in two consecutive years (or the change is very small), the urban growth equilibrium is achieved. It is theoretically possible that the urban system does not converge and changes constantly among two or more distinct states.

Table 7.1. Four simulation experiments for Twin Cities, MN

\begin{tabular}{|l|l|l|}
\hline $\begin{array}{l}\text { Allow for land } \\
\text { Initial use changes? }\end{array}$ & \multicolumn{1}{|c|}{ No } & Yes \\
condition & & \\
\hline $\begin{array}{l}1978 \text { Twin Cities network } \\
\text { with real 1978 capacity }\end{array}$ & Experiment 1 & Experiment 2 \\
\hline $\begin{array}{l}\text { 1978 network with uniform } \\
\text { capacity (400veh/h) }\end{array}$ & Experiment 3 & Experiment 4 \\
\hline
\end{tabular}


The four simulation experiments are carried out on a personal computer with a Dual-Core Intel processor at $3.2 \mathrm{GHz}$ with about the average computing speed of standard personal computers. On average, it takes about 12 minutes for each simulation iteration (i.e., one year of land use and transportation network evolution). The traffic assignment step in the transportation module consumes a major portion of the running time. There are a lot of road expansion activities at the beginning of the evolution process. As we can see in Figure 7.3, thousands of links are expanded in the first several years following 1978, according to the model. However, the network settles itself very quickly, and after about 25 years fewer than a hundred links still experience (relatively small) changes in capacity and free-flow speed. In order to achieve the strict equilibrium defined as a system with no more network or land use changes, it is necessary to continue the iterations for many more years at any network as large as the one in the Twin Cities metro area. But all significant changes occur during the first 20 years. It is clear the co-evolution model is approaching equilibrium smoothly. It is probably not practical (with this level of computer reality) to execute the model until a strict equilibrium is achieved. A goal function can be set up to determine the stopping point of the simulation. For instance, further iterations are not considered if the average percentage change of network capacity and land use density becomes less than 0.001 . The remaining presentation of the simulation results only focus on the system dynamics between 1978 and 1998 (i.e., the first twenty simulation iterations) since most important changes take place during this period. 

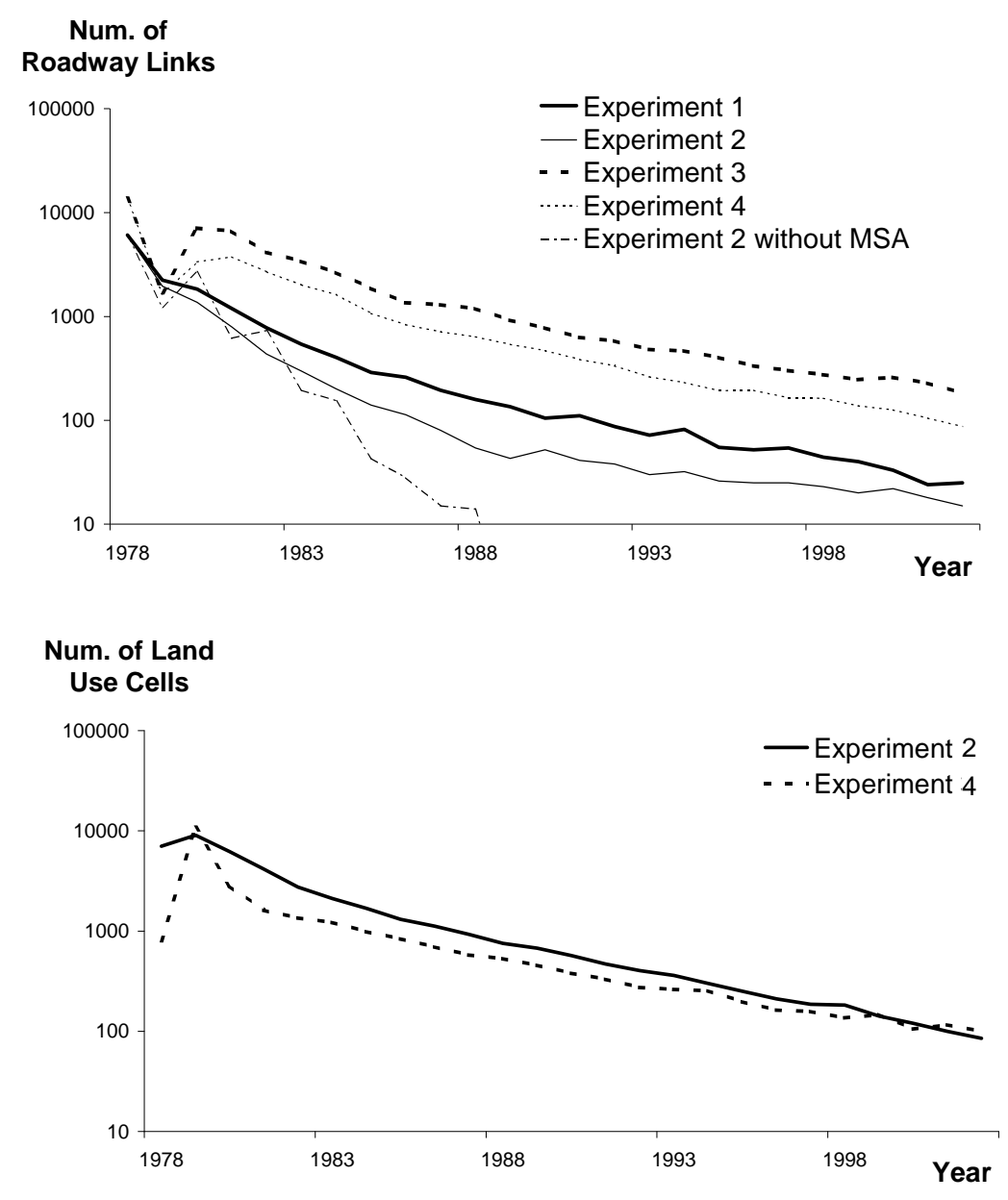

Figure 7.3. Convergence Properties of the Co-Evolution Model

In the travel demand model, an updating procedure similar to the Method of Successive Average (MSA) is adopted to take into account the impacts of lagged demand (see Equation 4.1). One may suspect that it is this MSA procedure that forces the system to achieve long-term equilibrium. In order to test this hypothesis, Experiment 2 with the fastest convergence is also executed without MSA (i.e., travel demand in the current year is independent of demand in previous years - only the second term on the right hand side of Equation 4.1 is left in this case). The convergence property without MSA is presented in Figure 7.3 as well, which rejects the hypothesis and suggests induced or latent demand actually hinders the equilibration process. 
This result is also intuitive - an urban system with factors delaying the adjustment of demand to changing supply, such as habitual behavior, uncertainty, and information acquisition cost, takes longer to reach its equilibrium than a system without those factors.

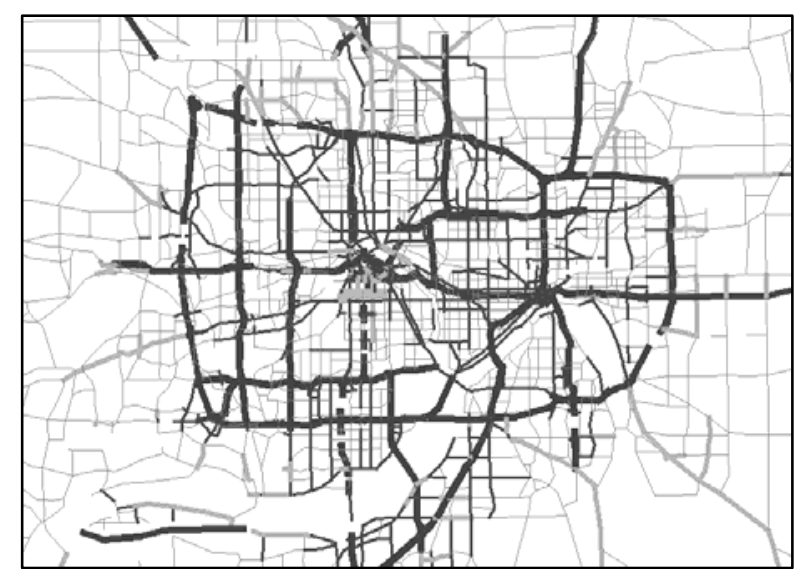

\section{Capacity}

$<272$ vehihr

- $273-913$ vehihr

- $914-1820$ vehihr

$1821-3207$ vehihr

> 3208 vehihr

$\longrightarrow$ Real growth

$\longrightarrow$ Predicted growth

(a) Base: observed 1978 network with real capacity

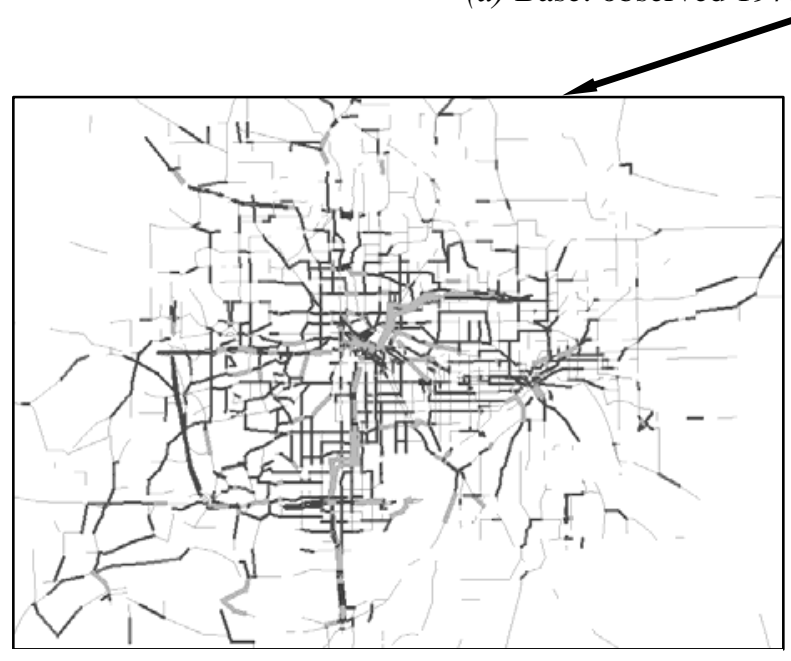

(b) Capacity change: observed 1998 - base

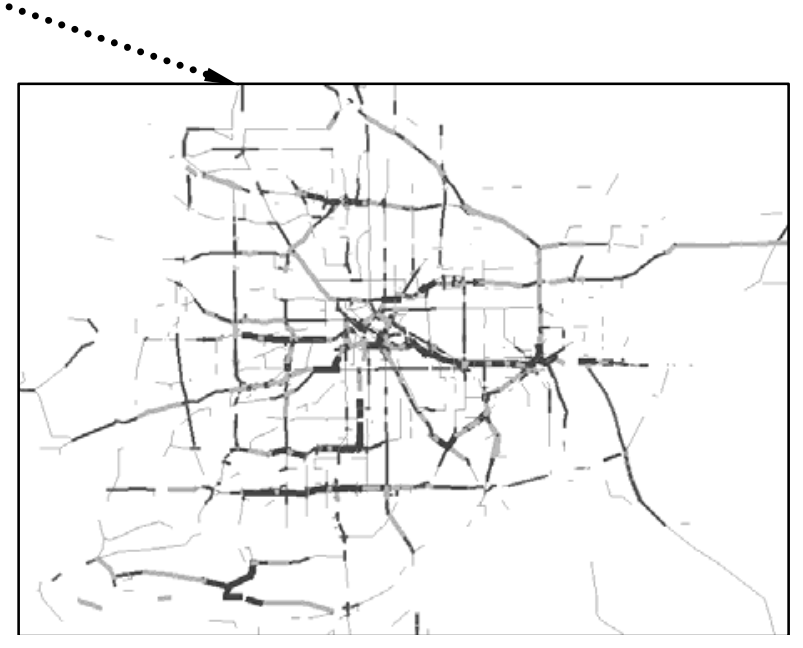

(c) Capacity change: Experiment 21998 - base

Figure 7.4. Experiment 2 vs. Observed Network Growth after 20 Years

Predicted road network expansions from the co-evolution model between 1978 and 1998 are compared with expansion activities that actually occurred during that period. Experiment 2 is the most realistic case of all four experiments because it starts with the observed 1978 road network and land use pattern, and allows both land use and transportation network changes 
between 1978 and 1998. In Figure 7.4, only the prediction results from Experiment 2 (7.4c) are compared to the observed transportation network capacity changes (7.4b). Figure 7.4a represents the initial conditions. Although the model successfully predicts several large freeway construction projects, it forecasts more expansions on roads already having high capacities (freeway segments), and fewer expansions on arterial roads than reality. There are several possible reasons for these biased estimates. The capacity expansion costs of arterial roads might have been overestimated or the costs of freeway capacity expansions underestimated in the model. The co-evolution model currently uses the same cost function for all roads in the model. There is clearly a need for cost functions adjusted to link-specific conditions. In addition, a lot of the preservation and expansion projects on arterial streets are for safety improvement, a consideration not included in the transportation module of the current co-evolution model.
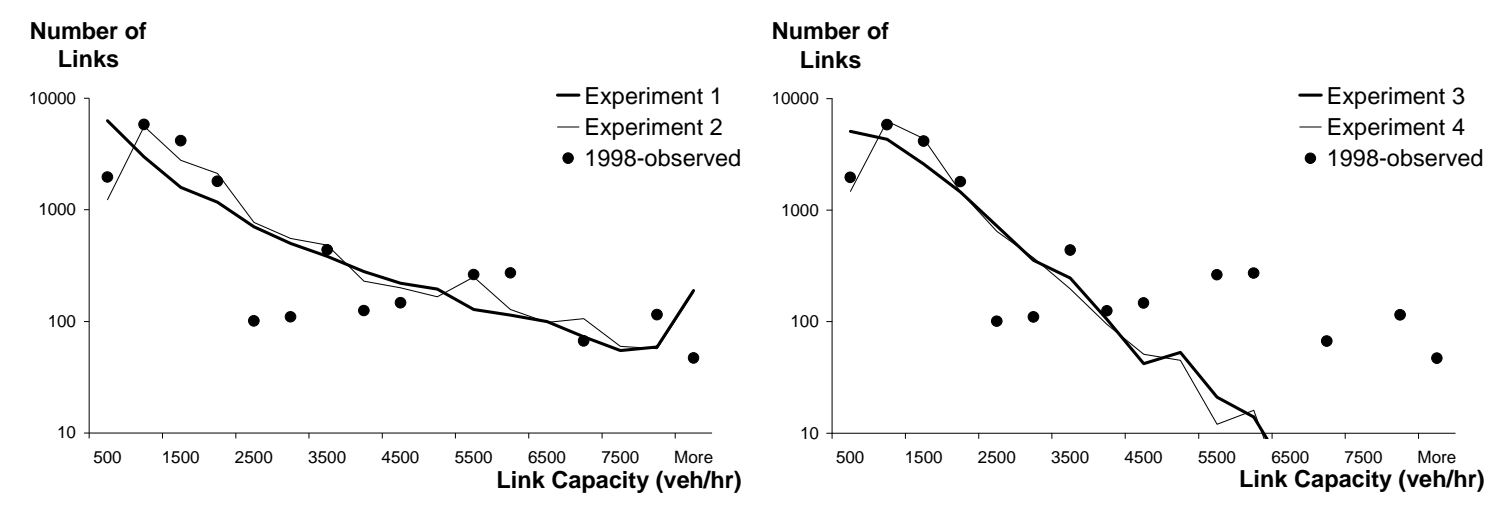

Figure 7.5. Road Hierarchy after 20 Years

Road hierarchy emerges in all four experiments (see Figure 7.5). In the predicted 1998 networks, most roads have low capacity and carry low flows, while only a few roads are expanded to very high capacities and carry the bulk of traffic. Experiments 1 and 2 start from the 1978 network with real capacity and, hence, the hierarchical structure is already present at the initial condition 
because the construction work of most freeways in the Twin Cites had been completed by 1978 . It is, therefore, not very surprising to see the predicted 1998 network hierarchy conforms very well with the observed 1998 data. With actual network data in the starting year (1978), the proposed co-evolution model with simple land use and transportation network growth models provides satisfactory forecasts of road hierarchy in future years. It is interesting to see that hierarchy also emerges in Experiments 3 and 4 where the starting condition is a uniform capacity network. The predicted hierarchies in these two scenarios are actually very close to the observed ones for lower-level roads. The results from Experiments 3 and 4 also suggest that if planners in the Twin Cities could design a brand-new network to serve the existing travel demand and replace the existing network, they would build many fewer roads with very high capacities, as seen on the right side of the two graphs. This finding may be somehow not very meaningful due to the big "if." How the network arranges itself in a hierarchical pattern from a uniform status is a really interesting question. To answer that question, the growth path of the Twin Cities network in Experiment 4 is presented in consecutive maps where changes in road capacity are shown with lines of different weights (Experiment 4 is shown because it allows for land use changes and, therefore, is more realistic). 


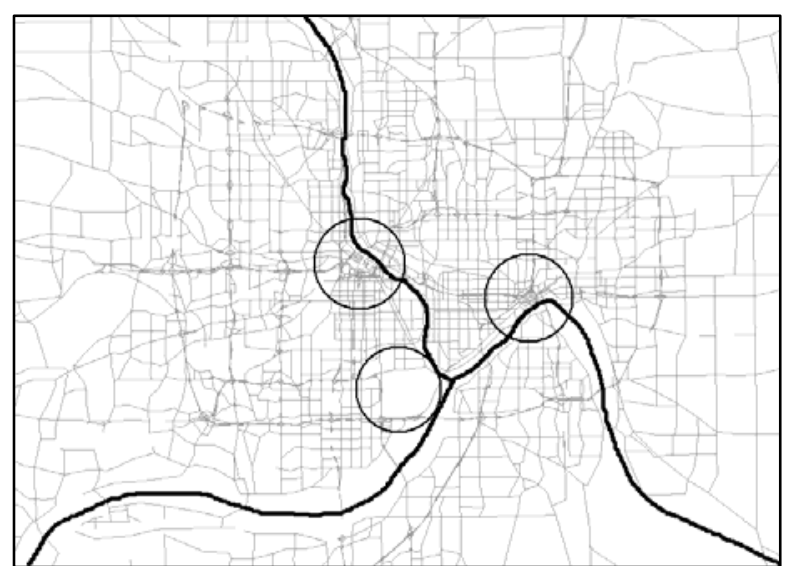

(a) Base: 1978 network with uniform capacity (400veh/h)

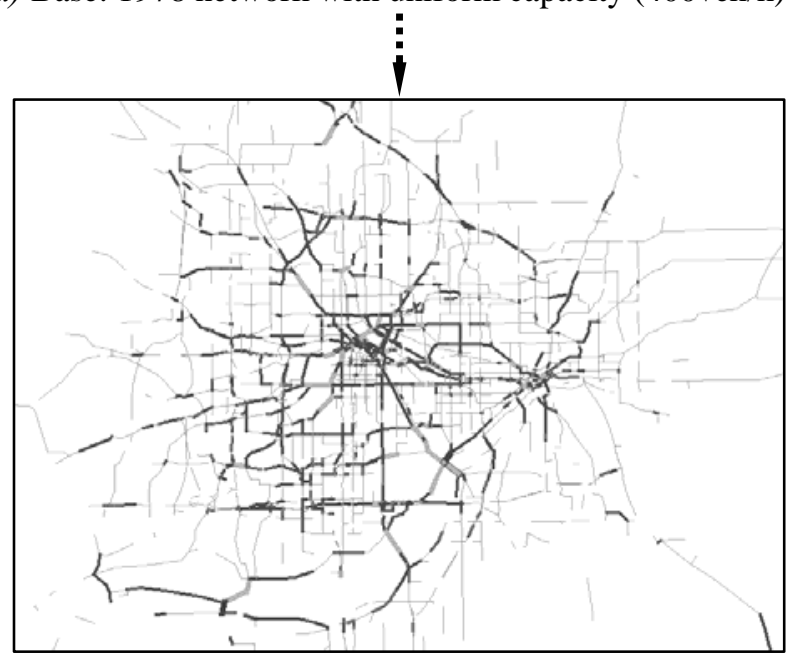

(b) Experiment 4 capacity change: predicted 1982 - base

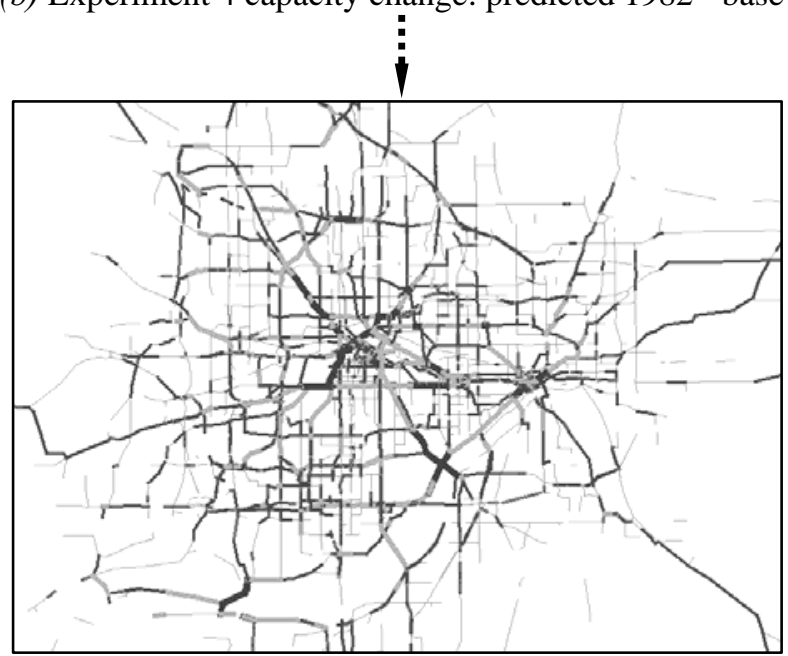

(c) Experiment 4 capacity change: predicted 1998 - base
Capacity $<272$ vehihr - 273- 913 vehihr - $914-1820$ vehihr - $1821-3207$ vehihr — 3208 vehihr

$\longrightarrow$ Real growth

....... Predicted growth

River

The three downtowns

Figure 7.6. Emergence of Hierarchies in Experiment 4 
For those who are not familiar with the Twin Cities metropolitan area, a brief description of the region's features may be helpful before the maps in Figure 7.6 are examined. Two traditional central business districts, downtown Minneapolis and downtown Saint Paul, are approximately 10 kilometers from each other. The Minnesota River meets the Mississippi River right in the city. At the confluence point of the two rivers is the region's international airport. A new suburban business area, downtown Bloomington, also has emerged near the airport. The three downtowns, as well as the rivers, are shown in the base year network (7.6a). After four years, the model predicts that some roads are expanded (7.6b). The location of these expansions tells us much about how road hierarchy emerges even from a uniform network. Natural barriers, such as rivers in this case, are sources of unbalanced road construction. It is clear that bridges are able to attract more flow than other roads in the network and hence get expanded first. Network effects then drive more flow to the roads emanating from bridges; for instance, the roads along riverbanks. If one carefully examines the roads surrounding the airport, the circle just west of the river conflux, it is evident these roads also are able to generate more revenues than an average road and are expanded early in the evolution process. The role of the airport here is much like some natural barriers such as mountains because they all direct more flow to bypasses. The second source of hierarchy comes from activity centers. The three downtowns, with a high density of jobs and other activities, are the areas with intense road expansions in the years following 1978. Finally, the fact that all major road expansions between 1978 and 1982 take place in the region's central area suggest that boundary effects also contribute to the formation of road hierarchy. Though we live on a round globe, even the largest metropolitan area today is still better modeled as a planar surface. Travel demand on a limited plane is not uniform. Most trips originating from the edges of the city are inward trips and destined for activity centers 
located relatively closer to the geographical center of the region, while trips emanating from areas in the middle of the city are distributed along all possible directions. The asymmetry in demand patterns is the third source of road hierarchy identifiable from the second map. Again, network effects will help propagate the hierarchical pattern created by those three sources throughout the whole network over time. Twenty years later, road hierarchy can be found virtually everywhere in the network (7.6c).
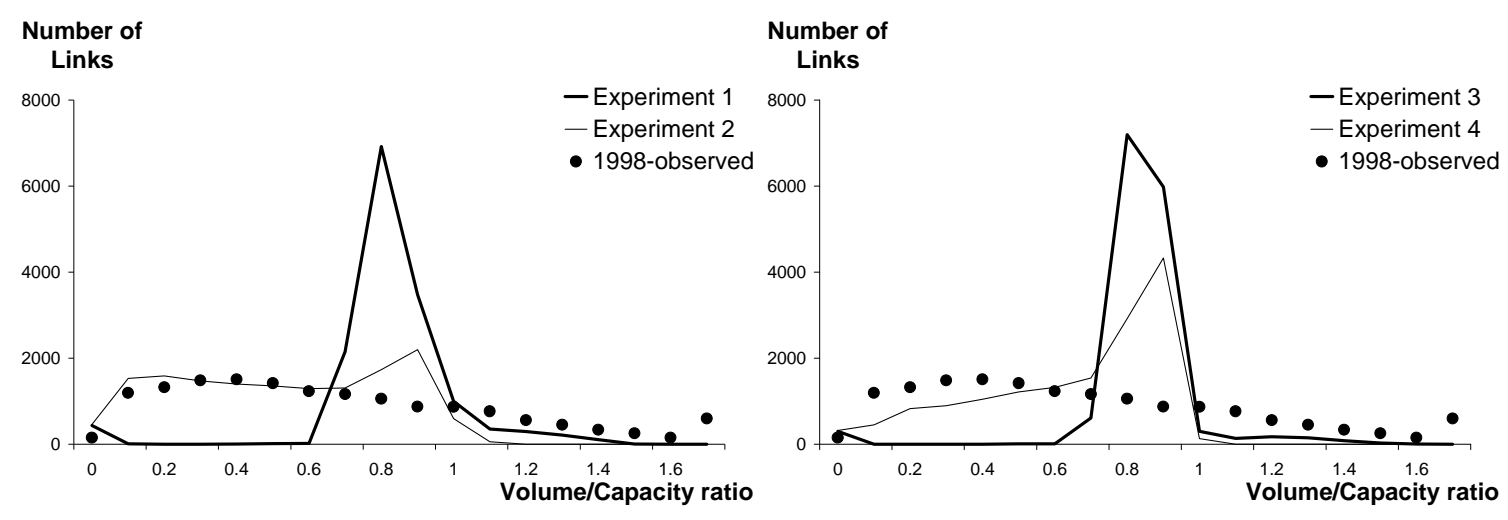

Figure 7.7. Network Congestion after 20 Years

Congestion is undesirable in an urban system and has attracted a lot of attention in land use and transportation analysis. In Figure 7.7, volume capacity ratios (VC ratios) of all roads in the urban system after 20 years of evolution are plotted in a histogram. The observed 1998 data suggest that most roads carry flows well below their capacity, and a few roads operate at VC ratios near or slightly higher than one. Practically, over a long period of time, no road can carry flows more than its capacity. The presence of VC ratios larger than one in the model is the result of inadequate description of road travel delays and scheduling adjustments in the traditional fourstep travel forecasting model used in our co-evolution model. Experiments 1 and 3 do not allow land use change and they show a narrow range of $\mathrm{VC}$ ratios, suggesting a more uniform 
distribution of congestion in the network. Note that the model does not say that at equilibrium a uniform distribution of VC ratios will be achieved. Road VC ratios in Experiments 1 and 3, which allow land use changes over time, are clearly different Experiments 2 and 4 . This highlights the importance of considering both land use and transportation network growths in an integrated co-evolution model. The spike near VC ratio of one is present in Experiments 2 and 4. This is probably because the same revenue and cost functions are applied to all roads. In reality, it may be more expensive to expand some roads than others and, hence, different levels of congestion are observed. This again suggests that cost and revenue functions in the model should be adjusted according to local conditions. 


\section{CONCLUSIONS}

An urban system is a very complex system that consists of a full spectrum of various subsystems, the properties and behaviors of which are already hard to forecast. Modeling the dynamics in an urban system is important yet challenging for transportation, planning, economic, and regional analyses. Significant research efforts have been devoted to travel demand forecasting, network design problems, revenue policies, and land use modeling by numerous researchers in the past several decades. Predicting the growth of transportation networks and changes in land use is difficult because it requires us to consider almost all sub-processes involved in urban dynamics. This project originates from the need to consider land use and transportation evolution jointly in a coherent theoretical and modeling framework (i.e., the need to model the co-evolution of land use and transportation).

Understanding the true relationships between supply and demand in land use and transportation systems is the crucial task in theoretical development of urban models. The difficulty also comes from practical issues, such as available data for model calibration and validation. Urban area socio-economic, demographic, land use and transportation network data from many years ago must be collected and coded consistently over time. Several unresolved issues further complicate the problem. The foremost one is whether land use and transportation network growth is simply designed by planners, or whether it indeed can be explained by underlying natural and market forces. In light of this debate, we would like to view this project as proof of the concept that some important system properties, such as road hierarchy, spatial agglomeration of activities, and self-organization in land use-transportation systems, can be predicted through a microscopic evolutionary process, a demonstration that such a microscopic agent-based model of network dynamics can be feasibly applied to large-scale realistic urban 
systems, and an enquiry into how this concept can be realized and produce useful modeling tools for planners.

This project models the co-evolution of land use and transportation as a bottom-up process by which the relocation of activities and expansion of roads are driven by interdependent decisions of individual households, firms, and transportation authorities. The agent-based simulation method is an appealing modeling approach for analyzing the simultaneous and interactive changes of land use and transportation systems over time. The prototype model is demonstrated and successfully applied to two case studies. It is shown that the co-evolution model is applicable to real-world, large-scale urban systems. An urban area may achieve longterm urban growth equilibrium (UGE) under the proposed theory of land use-transportation coevolution. At UGE, there is no incentive for a transportation user to unilaterally change travel behavior, for transportation authority to unilaterally expand or denigrate the transportation network, or for households or firms to unilaterally change their land use decisions. This equilibrium concept is useful when the co-evolution model is applied to evaluate or forge land use and/or transportation management decisions and policies.

The simulation experiments in particular examine the emergence of road networks and central places under the context of the land use-transportation co-evolution. Experimental results demonstrate that the agglomeration and centralization of road infrastructure is reinforced by the dynamics of employment and population, and that land use changes due to relocation decisions in the long run can reduce the demand for transportation infrastructure.

Several aspects of the proposed co-evolution model need to be improved in future research. The simulation model consists of several component models, including travel demand, location choice, land use change, transportation pricing/investment, and network capacity 
models. The prototype model presented in this report has not fully taken advantage of the stateof-the-art of these component models. In particular, travel demand and land use models based on micro-simulation should be considered in future improvement to the co-evolution model. The coevolution model has a number of coefficients, and only part of them have been empirically estimated and validated. Future research needs to collect necessary land use and transportation network data for the development of a fully operational co-evolution model of land use and transportation for a particular metropolitan area. 


\section{REFERENCES}

Adams, J. (1999) Measuring the Connections: Highway Improvements and Land Development Patterns in the Greater Twin Cities Area, 1970-1995. Report submitted to the Center of Transportation Studies, University of Minnesota. www.cts.umn.edu.

Aghion, P. and P. Howitt (1998) Endogenous growth theory. Cambridge MA, MIT Press.

Aschauer, D (1989) Is Public Expenditure Productive? Journal of Monetary Economics Mar 23a(2): 177-200.

Bar-Gera, H. and D. Boyce (2003) Origin-based algorithm for combined travel

forecasting models. Transportation Research 37B(5): 405-22

Barker, T.C. and M. Robbins. (1975) A History of London Transport, Volume 1 and 2. Allen and Unwin, London

Barra, T. de la, et. al. (1989). TRANUS-J: Putting Large Models into Small Computers. Environment and Planning B 11: 87 - 101

Batty, M. and Longley, P. (1985) The Fractal Simulation Of Urban Structure / by Cardiff, Wales: Department of Town Planning, University of Wales Institute of Science and Technology, Papers in planning research; 92.

Boarnet, M. (1997) Infrastructure Services and the Productivity of Public Capital: The Case of Streets and Highways. National Tax Journal 50(1): 39-57, March, 1997

BTS (Bureau of Transportation Statistics) (2002) Transportation Indicators http://www.bts.gov/transtu/indicators/Transportation_System_Extent_and_Use.html (Accessed June 12, 2002)

Button (1998) Infrastructure investment, endogenous growth and economic convergence. Annals of Regional Science 32(1): 145-62 
Burns, L. (1979) Transportation, Temporal and Spatial Components of Accessibility, Lexington MA: Lexington Books.

Caruthers, J.I., and Ulfarsson, G.F., (2001): Public Service Expenditures: The Influence of Density and Other Characteristics of Urban Development . The Pacific Regional Science Conference Organization. Conference in Portland OR July 2001

Christaller, W. (1966) Central places in southern Germany. Englewood Cliffs, New Jersey Prentice Hall (Translated by Carlisle W. Baskin)

Conder, S. (2001) Metroscope Documentation. Technical Report, Portland Metro.

Clark, C. (1968) Population Growth and Land Use, Macmillan, London.

De La Barra, T. (1989) Integrated Land Use and Transport Modeling. Cambridge: Cambrige University Press. $59 \sim 64$.

Ewing, R. (1997) Is Los Angeles Style Sprawl Desirable. Journal of the American Planning Association 63(1): 107-126.

Fulton, L.M., Noland, R.B., Meszler, D.J. and J.V. Thomas (2000) A statistical analysis of the induced travel effects in the US Mid-Atlantic region. Journal of Transportation and Statistics 3(1): 1-14

Garrison, W.L. and D.F. Marble (1965) A prolegomenon to the forecasting of transportation development. Office of Technical Services, US Department of Commerce, US Army Aviation Material Labs Technical Report

Gordon, P., and Wong, H.L. (1985) The Costs of Urban Sprawl - Some New Evidence. Environment and Planning A 17(5): 661-666.

Gordon, P., and Richardson, H.W. (1997) Are Compact Cities a Desirable Planning Goal? Journal of the American Planning Association 63(1): 95-106. 
Giuliano, G. (2004). Land Use Impacts of Transportation Investments: Highway and Transit. In Hanson, S. and Giuliano, G. (eds.), The Geography of Urban Transportation. New York: Guilford Press.

Greene, D.L. (1997) Sustainable transport. Journal of Transport Geography 5(3):177-190.

Gramlich, E. (1994) Infrastructure investment: a review essay. Journal of Economic Literature 32: $1176-1196$

Gregor, B. (2006). The Land Use Scenario DevelopeR (LUSDR): A Practical Land Use Model Using a Stochastic Microsimulation Framework. Submitted for Presentation at the 86th Annual Meeting of the Transportation Research Board.

Grübler, A. (1990) The rise and fall of infrastructures: dynamics of evolution and technological change in transport. Heidelberg: Physica-Verlag

Haynes, K.E. and A.S. Fotheringham (1984) Gravity and Spatial Interaction Models. Beverly Hills, CA: Sage Publications

Haj-Salem, H. and Papageorgiou, M. (1995) Ramp metering impact on urban corridor traffic: Field results. Transportation Research Part A 29(4): 303-319.

Handy, S. (1993) Regional Versus Local Accessibility: Implications for Nonwork Travel. Transportation Research Record 1400: 58-66.

Hansen, W.G. (1959) How Accessibility Shapes Land Use. Journal of the American Institute of Planners 25: 152-166.

Hanson, S. and Giuliano, G. (eds.) (2004). The Geography of Urban Transportation. New York: Guilford Press.

Hanson, S., and M. Schwab (1987) Accessibility and Intra-urban Travel. Environment and Planning A 19(6): 735-748. 
Hutchinson, B. G. (1974) Principles of Urban Transportation Systems Planning. New York: McGraw-Hill

Krugman, P. (1996) The Self-Organizing Economy. New York: Blackwell

Lee, C. (1973) Models in Planning. London: Pergamon Press.

Levinson, D., and A. Kumar (1995) A Multimodal Trip Distribution Model: Structure And Application. Transportation Research Record 1466:124-31.

Levinson, D. (1998) Accessibility and the Journey to Work. Journal of Transport Geography 6(1): 11-21.

Levinson, D., and Zhang, L. (2006). Ramp meters on trial: Evidence from the Twin Cities metering holidays. Transportation Research 40A (10): 810-828.

Levinson, D., Zhang, L., Das, S., and Sheikh, A. (2004). Evaluating the effectiveness of ramp meters. In Gillen, D. and Levinson, D. (editors), Assessing the Benefits and Costs of Intelligent Transportation Systems, Kluwer Academic Publishers.

Levinson, D. (1995) An evolutionary transportation planning model. Transportation Research Record 1493: 64-73

Levinson, D. and R. Karamalaputi (2003) Induced supply: a model of highway network expansion at the microscopic level. Journal of Transport Economics and Policy 37(3): 297-318

May, D., and H. Bogenberger (1999) Advanced Coordinated Traffic Responsive Ramp Metering Strategies. California PATH working paper UCB-ITS-PWP-99-19.

Miyagi, T. (1998) A spatial computable general equilibrium approach for measuring multiregional impacts of large scale transportation projects. Network Infrastructure and the Urban Environment, Springer, 224-44 
Miyao, T. (1981) Dynamic analysis of the urban economy. Academic Press, New York

Muth, R.F. (1969) Cities and Housing. Chicago: University of Chicago Press.

Nadiri, M. Ishaq and T. Mamuneas (1996) Contribution of highway capital to industry and national productivity growth. Federal Highway Adminstration

New Jersey Office of State Planning (1996) Projecting municipal road costs under various growth scenarios. Document Number 109

Newman, M.E.J. (2001) The structure and function of networks. Computer Physics and Communications 147: 40-45

Noland, R.B. (1998) Relationship between highway capacity and induced vehicle travel. Transportation Research Board $78^{\text {th }}$ Annual Meeting Preprint CD-ROM, Transportation Research Board, National Research Council, Washington DC

Payne-Maxie Consultants (1980) The Land Use and Urban Development Impacts of Beltways, Final Report No. DOT-0S-90079, U.S. DOT \& DHUD, Washington, D.C.

Parthasarathi, P., Levinson, D., and R. Karamalaputi (2003) Induced demand: a microscopic perspective. Urban Studies 40(7): 1335-1353

Peat F.D. (2002) From certainty to uncertainty: the story of science and ideas in the twentieth century. National Academy Press: Washington DC p.xiii

Roberts, M and D. Simmonds (1997). A strategic modeling approach for urban transport policy development. Traffic Engineering and Control 38(7): 377-384.

Schelling, T. C. (1969) Models of segregation. American Economic Review59(2): 488- 93

Sheffi, Y. (1985) Urban transportation networks. Prentice-Hall, Englewood Cliffs, NJ

Smock, R.J. (1962) An iterative assignment approach to capacity restraint on arterial networks. Highway Research Board Bulletin 156: 1-13 
Strathman, J.G., Dueker, K.J., Sanchez, T., Zhang, J., and A.E. Riis (2000) Analysis of induced travel in the 1995 NPTS. Center for Urban Studies, Portland State University

Taffe, E.J., Morrill, R.L., and P.R. Gould (1963) Transport expansion in underdeveloped countries: a comparative analysis. Geographical Review 53 (4): 503-29

Vaughan, R. (1987) Urban Spatial Traffic Patterns, Pion Limited, London

Von Neumann, J. (1966) Theory of Self-Reproducing Automata. Edited by A. W. Burks. University of Illinois Press

Waddell (2001) UrbanSim: modeling urban development for land use, transportation, and environment planing. Paper presented to the $17^{\text {th }}$ Pacific Conference of the Regional Science Association, June 30-July4, 2001

Wardrop, J.G. (1952) Some theoretical aspects of road traffic research. Proceedings of the Institution of Civil Engineers, Part II, 1(36): 325-62

Webster F.V, Bly, P.H., and N.J. Paulley (editors) (1988) Urban land-use and transport interaction: Policies and models. The report of the International Study Group on Land Use/ Transport Interaction (ISGLUTI), Gower.

Williams, P.A. (1989) The Influence of Residential Accessibility on Household Trip Making. Socioeconomic Planning Sciences 23(6): 373-385.

Wolfram, S. (1994) Cellular Automata and Complexity. MA: Addison-Wesley.

Wolfram, S. (2002) A New Kind of Science. Champaign, IL: Wolfram Media.

Yamins D., Rasmussen, S. and D. Fogel (2003) Growing urban roads. Networks and Spatial Economics 3: 69-85

Yerra, B. and D. Levinson (2002) The emergence of hierarchy in Transportation networks. Under review Annals of Regional Science. 
Zhang, L. (2006). Traffic diversion effect of ramp metering. Journal of the Transportation Research Board (In Press).

Zhang, L., and Levinson, D. (2004). Optimal freeway ramp control without origin-destination Information. Transportation Research 38B (10): 869-887.

Zhang, L., and Levinson, D. (2005). Balancing efficiency and equity of ramp meters. ASCE Journal of Transportation Engineering 131 (6): 477-481.

Zhang, L., and Levinson, D. (2006). Ramp metering and freeway bottleneck capacity. Transportation Research A (Accepted for Publication).

Zhang, L. (2008) Do freeway operations exacerbate urban sprawl? Transportation Geography (under review).

Zhang, L., and Levinson, D. (2008) An agent-based model of price competition and product differentiation on congested networks. Journal of Transportation Economics and Policy (forthcoming).

Zhang, L., and Levinson, D. (2006). The economics of transportation network growth. In Coto, P., and I. Vicente (Eds.), Essays on Transportation Economics. Springer Science.

Zhang, L., and Levinson, D. (2005) Road pricing with autonomous links. Journal of the Transportation Research Board 1932: 147-155.

Zhang, L., Developing a positive approach to travel demand forecasting: Theory and model. Traffic and Transportation Theory 17, London (Accepted for publication).

Zhang, L., and Levinson, D. (2004). An agent-based approach to travel demand forecasting: An exploratory analysis. Journal of the Transportation Research Board 1898: 28-36. 




\section{AOTREC \\ OREGON TRANSPORTATION RESEARCH \\ AND EDUCATION CONSORTIUM}

\section{P.O. Box 751}

Portland, OR 97207

OTREC is dedicated to stimulating and conducting collaborative multi-disciplinary research on multi-modal surface transportation issues, educating a diverse array of current practitioners and future leaders in the transportation field, and encouraging implementation of relevant research results. 